\title{
O6-methylguanine-DNA methyltransferase modulates cisplatin-induced DNA double-strand breaks by targeting the homologous recombination pathway in nasopharyngeal carcinoma
}

Shang-Hung Chen 1,2, Wen-Tsung Huang ${ }^{3}$, Wan-Chen Kao ${ }^{3}$, Sheng-Yen Hsiao ${ }^{3,4}$, Hsin-Yi Pan ${ }^{1}$, Chin-Wen Fang ${ }^{1}$, Yow-Ling Shiue ${ }^{5}$, Chia-Lin Chou ${ }^{5,6^{*}}$ and Chien-Feng Li ${ }^{1,7,8^{*}}$

\begin{abstract}
Background: The homologous recombination (HR) pathway is involved in DNA damage response (DDR), which is crucial to cancer cell survival after treatment with DNA damage agents. O6-methylguanine DNA methyltransferase (MGMT) is associated with cisplatin (CDDP) resistance in cancer cells; however, the underlying mechanisms remain unclear. Here, we explored the interactions between MGMT and the HR pathway in CDDP-activated DDR and their clinical implications in nasopharyngeal carcinoma (NPC).

Methods: Human NPC cells were assessed using loss-of-function approaches in vitro. The expression correlations between MGMT and major proteins of the HR pathway were analyzed through Western blotting, quantitative realtime PCR, and bioinformatic analysis by using a public database. The physical interactions between MGMT and HR proteins were studied using co-immunoprecipitation and immunofluorescence analyses. Cell comet tails and $\gamma-\mathrm{H} 2 \mathrm{AX}$ expression levels were examined to evaluate double-strand break (DSB) formation. Established immunofluorescence and reporter analyses were conducted to measure HR activity. Xenograft and cell viability studies were used to assess the therapeutic potential of MGMT inhibition in combination with CDDP and poly(ADP-ribose) polymerase (PARP) inhibitor, respectively.

Results: Among major proteins of the HR pathway, MGMT suppression inhibited CDDP-induced RAD51 expression. Bioinformatic analyses showed a positive correlation between MGMT and RAD51 expression in patients with NPC. Moreover, MGMT physically interacted with BRCA1 and regulated CDDP-induced BRCA1 phosphorylation (ser 988). In functional assays, MGMT inhibition increased CDDP-induced DSB formation through attenuation of HR activity. NPC xenograft studies demonstrated that MGMT inhibition combined with CDDP treatment reduced tumor size and
\end{abstract}

\footnotetext{
*Correspondence: clchou3@gmail.com; angelo.p@yahoo.com.tw

${ }^{6}$ Division of Colon and Rectal Surgery, Department of Surgery, Chi Mei

Medical Center, No. 901, Zhonghua Rd., Yongkang Dist., Tainan 71004,

Taiwan

${ }^{8}$ Institute of Precision Medicine, National Sun Yat-sen University, No.70,

Lien-hai Rd., Kaohsiung 80424, Taiwan

Full list of author information is available at the end of the article
}

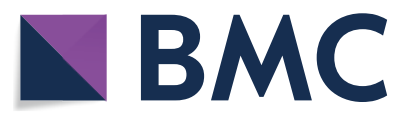

(c) The Author(s) 2021. Open Access This article is licensed under a Creative Commons Attribution 4.0 International License, which permits use, sharing, adaptation, distribution and reproduction in any medium or format, as long as you give appropriate credit to the original author(s) and the source, provide a link to the Creative Commons licence, and indicate if changes were made. The images or other third party material in this article are included in the article's Creative Commons licence, unless indicated otherwise in a credit line to the material. If material is not included in the article's Creative Commons licence and your intended use is not permitted by statutory regulation or exceeds the permitted use, you will need to obtain permission directly from the copyright holder. To view a copy of this licence, visit http://creativecommons.org/licenses/by/4.0/. The Creative Commons Public Domain Dedication waiver (http://creativeco mmons.org/publicdomain/zero/1.0/) applies to the data made available in this article, unless otherwise stated in a credit line to the data. 
downregulated RAD51 expression and BRCA1 phosphorylation. Furthermore, MGMT suppression increased PARP inhibitor-induced cell death and DSB formation in NPC cells.

Conclusion: MGMT is crucial in the activation of the HR pathway and regulates DDR in NPC cells treated with CDDP and PARP inhibitor. Thus, MGMT is a promising therapeutic target for cancer treatments involving HR-associated DDR.

Keywords: MGMT, Cisplatin, Homologous recombination, PARP inhibitor, Nasopharyngeal carcinoma

\section{Background}

Nasopharyngeal carcinoma (NPC), a group of malignant diseases categorized into head and neck cancers, is considered endemic in Southeast Asian countries, including Taiwan $[1,2]$. Owing to anatomic characteristics different from those of other head and neck cancers, the main treatment strategy for locally advanced NPC is cisplatin (CDDP)-based chemoradiotherapy (CRT). Several randomized clinical trials have demonstrated that CDDP-based CRT significantly improved the overall survival of patients with advanced-stage NPC [3-5]. Moreover, because of the high response rates in tumor control, CDDP-based chemotherapy regimens are recommended as the first-line treatment in patients with metastatic NPC [6, 7]. Therefore, methods of overcoming CDDP resistance in patients with NPC requires further exploration.

CDDP, a platinum-based anticancer agent, is effective against several types of human cancers $[8,9]$. In general, CDDP can induce apoptotic cell death through platinum-DNA adduct formation. Given that this type of DNA damage is the major factor contributing to CDDP cytotoxicity, many DNA repair systems, such as nucleotide excision repair (NER) and mismatch repair, have been identified to be involved in CDDP resistance in cancer cells [10]. Furthermore, platinum-DNA adduct formation can lead to DNA double-strand breaks (DSBs), which is the most lethal type of DNA damage. This DNA damage can trigger DNA damage response (DDR), an intricate signaling network composed of various DNA repair systems in cancer cells. Of the DNA repair pathways, homologous recombination (HR) repair is a major repair system responsible for DNA DSBs [11]. After DSB formation, $\mathrm{HR}$ repair is initiated by the essential effectors BRCA1 and BRCA2. These effectors work together to facilitate DSB end resection and promote the recruitment of RAD51 to the damage site. The formation of RAD51coated filaments on DNA can induce DNA strand repair by searching the homologous chromatid. Notably, tumor cells with BRCA1 or BRCA2 dysfunction are susceptible to poly(ADP-ribose) polymerase (PARP) inhibitors [12, 13]. The primary function of DNA repair enzymes of the PARP family is DDR detection and initiation induced by DNA single-strand breaks (SSBs). Because the HR pathway is the major repair system of DSBs in cancer cells, the accumulation of SSBs caused by PARP inhibition can lead to increased DSB formation and subsequent cell death. Moreover, laboratory studies have demonstrated that the activity of the HR system is correlated with CDDP cytotoxicity in cancer cells [14-16]. Collectively, these results indicate that the HR pathway can be a feasible target in cancer treatment with DNA damage agents.

O6-methylguanine-DNA methyltransferase (MGMT) is a DNA repair enzyme that plays a role in protecting cells from cytotoxic effects of alkylating agents, especially those generating O6-alkylguanines [17]. This enzyme can repair DNA through the transfer of alkylating adducts from the $\mathrm{O} 6$ position of guanine in DNA to its cysteine residue (Cys145), the active site of this protein. Notably, we previously identified the prognostic value of MGMT expression levels in patients with NPC receiving CDDPbased CRT. In this study, high MGMT expression levels in NPC cells were correlated with low survival rates in patients treated with CDDP-based CRT [18]. Accumulating evidence is indicating that high MGMT expression levels can predict worse survival in patients with various types of cancers treated with platinum-based chemotherapy regimens [19-21]. In in vitro functional studies, we demonstrated that MGMT mediated CDDP-induced cytotoxicity and DNA repair activity in NPC cells [18]. Moreover, a study demonstrated that MGMT physically interacts with the molecular complex containing BRCA2 and is associated with BRCA2 degradation [22]. In mRNA expression analyses of profiled DNA damageassociated genes, we found that MGMT inhibition significantly reduced $R A D 51$ expression in NPC cells. These results suggest that MGMT may play a role in CDDPinduced DDR through involvement in HR signaling in cancer cells. Therefore, here, we investigated the molecular crosslinking between MGMT and the HR pathway and its clinical implications in NPC cells.

\section{Methods \\ Cell culture}

Human NPC cell lines, HONE-1 and TW01, were initially derived from patients with NPC [23, 24]. Topgen Biotechnology (Kaohsiung, Taiwan) authenticated these cell lines by using the short tandem repeat profile. These NPC cells were routinely culture as described previously [18]. 


\section{Antibodies and reagents}

Monoclonal anti-MGMT antibodies were obtained from LTK BioLaboratories (Taoyuan, Taiwan). Chemical agents including O6-benzylguanine (O6BG) and olaparib and antibodies targeting BRCA1, pBRCA1 (Ser988), BRCA2, RAD51, $\beta$-actin, and lamin A/C were purchased from Santa Cruz Biotechnology (Dallas, TX, USA). Monoclonal anti- $\gamma-\mathrm{H} 2 \mathrm{AX}$ antibodies were purchased from Cell Signaling Technology (Danvers, MA, USA). Other experimental reagents used are listed in a previous report [18].

\section{Human DNA damage signaling gene profiling}

The relative mRNA expression of genes involved in DNA damage signaling were examined using an $\mathrm{RT}^{2}$ Profiler PCR array (Catalog No. PAHS-029Z, Human DNA Damage Signaling Pathway, Qiagen) according to manufacturer's protocol. In brief, after HONE- cells were treated with or without O6BG $(120 \mu \mathrm{M})$ for $8 \mathrm{~h}$, total RNA was extracted using Qiagen columns (Qiagen, Valencia, CA, USA) and reverse transcribed using the SuperScript First Strand Synthesis System (Invitrogen Life Technologies). After the cDNA was applied to the Profiler PCR array, real-time PCR was performed using the ABI 7500 sequence detection system (Applied Biosystems) and PCR master mix (SA Biosciences $\mathrm{RT}^{2}$ qPCR Master Mix; Qiagen) for SYBR Green detection. Samples were amplified under the following conditions: a precycling hold at $95{ }^{\circ} \mathrm{C}$ for $5 \mathrm{~min}, 40$ cycles of denaturation at $95{ }^{\circ} \mathrm{C}$ for $15 \mathrm{~s}$ and annealing at $60{ }^{\circ} \mathrm{C}$ for $1 \mathrm{~min}$. Changes in mRNA expression were analyzed using $\Delta \Delta \mathrm{Ct}$ method and quantified by expression normalization with some housekeeping genes $(A C T B$, $B 2 M$, and GAPDH).

\section{Western blot analysis}

Western blot analyses were performed as described previously [18]. In brief, cells were lysed in lysis buffer (Merck Millipore, Darmstadt, Germany) and then the extracted proteins were separated through sodium dodecyl sulfate polyacrylamide gel electrophoresis and subsequently transferred onto polyvinylidene fluoride membranes (Merck Millipore, Darmstadt, Germany). The nuclear proteins were extracted using a commercial fractionation kit (Abcam, Cambridge, UK) according to the manufacturer's protocol. The immunoreactive signals of the membranes were detected using the Western Lightning Plus-ECL Enhanced Chemiluminescence Substrate (PerkinElmer, Inc., Waltham, MA, USA) and KodakX-Omat film (Kodak, Chalon/Paris, France). The band densities of immunoblotting were quantified using
ImageJ densitometry analysis and normalized to $\beta$-actin or lamin $\mathrm{A} / \mathrm{C}$ protein levels.

\section{Quantitative real-time PCR}

For quantitative real-time PCR (qPCR), NPC cells were lysed in TRIzol reagent (Invitrogen, Carlsbad, CA, USA). Total RNA was isolated using Qiagen columns (Qiagen, Valencia, CA, USA) and reverse transcribed using the SuperScript First Strand Synthesis System (Invitrogen Life Technologies). TaqMan gene expression assay kits for RAD51 (Hs00947967_m1) were purchased from Applied Biosystems (Carlsbad, CA, USA). The relative mRNA levels of RAD51 were detected using the ABI 7500 sequence detection system (Applied Biosystems) and calculated using the $\triangle \triangle \mathrm{Ct}$ method, with GAPDH mRNA as an endogenous control.

\section{Transient knockdown using small interfering RNA transfection}

For MGMT silencing, small interfering RNA (siRNA) duplexes were designed to target two separate coding regions: 5'-AAGCTGGAGCTGTCTGGTTGT-3' (nucleotides 52-71) and 5'-AAGGTTGTGAAATTCGGA GAA-3' (nucleotides 310-330). For nontarget silencing, the siRNA sequence targeting the coding region $5^{\prime}$-GCC ATTCTATCCTCTAGAGGATG-3' of luciferase was designated. NPC cells in the exponential growth phase were transfected with the siRNA duplex using Lipofectamine 2000 (Thermo Fisher Scientific, Waltham, MA, USA) according to the manufacturer's instructions. Detailed siRNA transfection conditions were described elsewhere [18].

\section{Correlation analyses using data from the Gene Expression Omnibus database}

For correlation analysis of gene expression levels, the clinical transcriptomes of NPC tumors were obtained from the Gene Expression Omnibus database (accession GSE102349) by using the Illumina HiSeq 2000 platform. This NPC cohort comprised 113 fresh tumor specimens with no treatment [25]. We analyzed the correlation between MGMT and RAD51 expression levels by using Pearson correlation analyses.

\section{Immunoprecipitation assay}

Co-immunoprecipitation (Co-IP) analyses were conducted according to a previous report [26]. To exclude the contaminating effect of DNA attached to tested proteins, $20 \mathrm{U} / \mathrm{ml}$ of DNase I (Roche) was added in lysis buffer. In brief, the cell lysates were subsequently sonicated, washed, and incubated with anti-MGMT antibodies (Abcam) or negative control IgGs (Santa Cruz Biotechnology). After incubation for $24 \mathrm{~h}$, Pierce Protein 
A/G UltraLink Resin (Thermo Fisher Scientific) was added to capture immune complexes. After washing, the precipitated proteins were resuspended in nonreducing loading buffer and heated at $95^{\circ} \mathrm{C}$ for 5 min before Western blot analyses.

\section{Immunofluorescence assay}

The immunofluorescence analyses were performed according to two previous reports [26, 27]. After the indicated treatment, NPC cells were fixed in $4 \%$ paraformaldehyde for $20 \mathrm{~min}$, permeabilized with a $0.05 \%$ Triton X-100 in TBS for $20 \mathrm{~min}$, and then blocked with $3 \%$ BSA for $1 \mathrm{~h}$. The NPC cells were then incubated with specific antibodies at $4{ }^{\circ} \mathrm{C}$ overnight. The dilution conditions for the antibodies used were as follows: 1:200 for anti-MGMT, 1:500 for anti-BRCA1 and anti- $\gamma \mathrm{H} 2 \mathrm{AX}$, and 1:1000 for anti-RAD51 antibodies. Specific secondary antibodies, Alexa-488 and Alexa-594 (Thermo Fisher Scientific, Waltham, MA, USA), were diluted at 1:1000 and incubated at room temperature for $1 \mathrm{~h}$. Nuclei were stained with DAPI (Sigma-Aldrich, St. Louis, MO, USA) at room temperature for $10 \mathrm{~min}$. Cells were mounted with Dako fluorescent mounting medium (Agilent Technologies, CA, USA), and the images were captured on an Olympus FV1000 Laser Confocal Microscope. The fluorescence intensities within NPC cells were analyzed using the FV10-ASW 4.0 viewer.

\section{Proximity ligation assay (PLA)}

After CDDP treatment $(10 \mu \mathrm{M})$ for $24 \mathrm{~h}, \mathrm{HONE}-1$ cells were subjected to PLA as described previously [28]. In brief, tested cells were first fixed with paraformaldehyde for $15 \mathrm{~min}$, and subsequently permeabilized with PBS containing Triton X-100 (Calbiochem) for $30 \mathrm{~min}$. After permeabilization, tested cells were blocked in Blocking Solution (Sigma-Aldrich) at $37^{\circ} \mathrm{C}$ for $1 \mathrm{~h}$, and then incubated with primary anti-MGMT (LTK BioLaboratories, Taoyuan, Taiwan) and BRCA1 antibodies (Santa Cruz Biotechnology, Dallas, TX, USA) at $4{ }^{\circ} \mathrm{C}$ overnight. Following incubation with primary antibodies, tested cells were successively incubated with PLA probes in antibody diluent for at $37^{\circ} \mathrm{C}$ for $1 \mathrm{~h}$, ligation solution at $37^{\circ} \mathrm{C}$ for $30 \mathrm{~min}$, and amplification solution at $37{ }^{\circ} \mathrm{C}$ for $100 \mathrm{~min}$. After the addition of Duolink in situ mounting medium (Sigma-Aldrich) and DAPI for $10 \mathrm{~min}$, immunofluorescence images were captured with a confocal microscope (FV1000, Olympus).

\section{Neutral comet assay}

The neutral comet assay was performed as described previously [28]. In brief, after being subjected to the indicated treatment, NPC cells were mixed with 100 $\mu \mathrm{L}$ of $1.5 \%$ low-melting point agarose and pipetted onto microscopic slides coated with $100 \mu \mathrm{L}$ of $1 \%$ normal melting point agarose at $4{ }^{\circ} \mathrm{C}$ for $15 \mathrm{~min}$. After gel adhesion, the cell slides were treated with neutral lysis solution for $20 \mathrm{~min}$. Electrophoresis was performed using the neutral electrophoresis buffer at $25 \mathrm{~V}$ (current $300 \mathrm{~mA}$ ) for $20 \mathrm{~min}$. After electrophoresis, the cell slides were incubated in a neutralizing buffer for $20 \mathrm{~min}$. The cell slides were then stained with propidium iodide (PI) and examined under a fluorescence microscope (Nikon, Optiphot-2, Tokyo, Japan) at $40 \times$ magnification. Microscopic images of the cell tails were scored using CometScore (TriTek, Sumeduck, VA, USA).

\section{Measurement of HR activity}

HR activity was analyzed using a PCR-based HR assay kit (Norgen Biotek, ON, Canada) according to the manufacturer's instruction. In brief, NPC cells were first transfected with two plasmids containing different mutations in their lacZ coding region for $24 \mathrm{~h}$ and then treated with O6BG at indicated concentrations for $8 \mathrm{~h}$. For siRNAtransfected NPC cells, HR reporting plasmids were cotransfected for $24 \mathrm{~h}$. For the PCR reaction, a set of universal primers amplifying all plasmid DNA was used as control for transfection efficiency. Another set of primers amplifying plasmid DNA generated by HR was used to measure repair activity. The level of recombinant DNA produced in experimental cells was analyzed using the $\Delta \Delta \mathrm{Ct}$ method and expressed as a ratio to the control cells.

\section{Xenograft studies}

All animal experiments were approved by the Institutional Animal Care and Use Committee of Chi-Mei Medical Center (approval number: 102120606) and conducted in accordance with the Guide for the Care and Use of Laboratory Animals. At first, $2 \times 10^{6}$ HONE- 1 cells mixed with Matrigel (Collaborative Research) were subcutaneously inoculated in the right flanks of male BALB/c nude mice (BioLASCO Co., Ltd, Taipei, Taiwan). The tumor volume $\left(\mathrm{V}, \mathrm{mm}^{3}\right)$ was calculated as $\mathrm{V}=\pi / 6 \times$ length $(\mathrm{mm}) \times$ width $^{2}\left(\mathrm{~mm}^{2}\right)$. When the size of growing tumors reached $\geq 100 \mathrm{~mm}^{3}$, the indicated treatment was started in the NPC xenografts. The study xenografts were randomized into four groups $(n=6$ in each group): (a) daily intraperitoneal (i.p.) injections of $1 \times$ PBS (control group), (b) twice-weekly i.p. injections of CDDP (3 mg/kg), (c) daily i.p. injections of O6BG $(2.5 \mathrm{mg} / \mathrm{kg})$, and (d) i.p. injections of a combination of CDDP (two times/week) and O6BG (daily). Treatments were continued until the subcutaneous tumor size became approximately $2000 \mathrm{~mm}^{3}$. 


\section{(See figure on next page.)}

Fig. 1 MGMT inhibition suppressed CDDP-induced RAD51 expression in NPC cells. a A heat map showing the expression changes of DNA repair genes with statistical significance, by using RT2 ${ }^{2}$ Profiler PCR Array, in HONE-1 cells with or without O6BG treatment, respectively. After HONE-1 cells were treated with O6BG $(120 \mu \mathrm{M})$ for $8 \mathrm{~h}$, the extracted mRNA was subjected to gene expression analyses. $\mathbf{b}$ HONE-1 and c TW01 cells

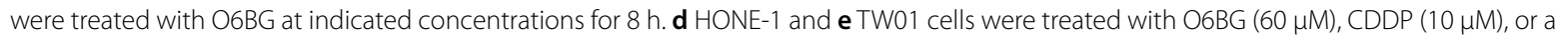
combination treatment for $8 \mathrm{~h}$. The $\mathrm{IC}_{50}$ concentration of O6BG in both HONE-1 and TW01 cells was $120 \mu \mathrm{M}$. After the indicated treatment, cell lysates were analyzed using Western blotting. Fold changes in protein levels listed under each blot were normalized to the levels of the actin control. Following single-drug or combination treatment as indicated in $\mathbf{d}$ and $\mathbf{e}$, the mRNA levels of $\mathbf{f} H \mathrm{HONE}-1$ and $\mathbf{g}$ TW01cells were quantified using QPCR. Representative results of at least three independent experiments are presented. Bar values are presented as mean \pm SD of at least three independent experiments. ${ }^{*} P<0.05$

\section{Immunohistochemical studies of xenografts}

After the mice were sacrificed, primary tumors in the flank were excised and weighed. Immunohistochemistry (IHC) staining procedures were performed based on a previous report [18]. Tumor tissues were routinely fixed in formalin and embedded in paraffin. The paraffinembedded tissue blocks were then cut into 3-mm-thick tissue slices. After routine deparaffinization and rehydration, slides were heated using a microwave treatment in citrate buffer $(\mathrm{pH} \mathrm{6)}$ ) for $7 \mathrm{~min}$ for antigen retrieval. Endogenous peroxidase was quenched using a $3 \% \mathrm{H}_{2} \mathrm{O}_{2}$ treatment. After a wash, slides were incubated with anti-MGMT, anti-RAD51, and anti-pBRCA1 antibodies for $1 \mathrm{~h}$, followed by secondary antibody incubation and hematoxylin counterstaining.

\section{Cell viability and clonogenic assay}

The cell viability and clonogenic assay were performed using methylene blue staining as previously described [26]. For the viability assay, NPC cells were initially seeded at $1 \times 10^{4}$ to $2 \times 10^{4}$ cells/well into 24 -well plates overnight for adhesion, and then subjected to the indicated treatment. For the clonogenic assay, NPC cells were first seeded at $5 \times 10^{3}$ to $8 \times 10^{3}$ cells/well into 6 -well plates overnight, followed by the indicated treatment for $24 \mathrm{~h}$. After a cell wash, the tested cells were incubated in treatment-free medium until colonies developed.

\section{Cell apoptosis analysis through annexin $\mathrm{V}$ and $\mathrm{PI}$ staining}

A commercial annexin V-FITC apoptosis detection kit (Thermo Fisher Scientific) was used to evaluate cell apoptosis as described previously [18]. NPC cells were first seeded in $10-\mathrm{cm}^{2}$ cell culture plates at a density of $1 \times 10^{6}$ to $2 \times 10^{6}$ cells per plate, followed by the indicated treatment when the cell densities reached $70-80 \%$ confluency. Following treatment, cells were routinely trypsinized, washed, and resuspended in annexin $\mathrm{V}$ staining buffer according to the manufacturer's protocol. After incubation for $20 \mathrm{~min}$ at room temperature in the dark, the annexin V and PI staining intensities of the test samples were detected using a FACS Calibur flow cytometer (BD Biosciences) and analyzed using CellQuest (BD Biosciences).

\section{Statistical analysis}

All assays were conducted at least in triplicate. The results, presented as means \pm their standard deviations (SDs), were compared using Wilcoxon rank-sum test on SPSS (version 20.0; IBM Corp, Armonk, NY, USA). Statistically significant differences were considered at $P<0.05$.

\section{Results \\ MGMT correlates with RAD51 expression in NPC cells}

To evaluate the molecular interaction between MGMT and other DNA repair effectors, we first examined the expression levels of 84 genes involved in the DNA repair pathway using $\mathrm{RT}^{2}$ Profiler PCR Arrays in HONE-1 cells. If the cut-off point was defined as the gene expression fold change of more than \pm 2 and $P$ value $<0.0001$, we identified 16 DNA repair-associated genes differentially expressed in NPC cells with pharmacological MGMT inhibition (O6BG treatment). These 16 identified genes were all downregulated by O6BG treatment, and foldchange of RAD51 expression was the largest among expression changes of these genes (Fig. 1a). To further determine the correlation between MGMT expression and the HR signaling pathway, we investigated the expression levels of HR-associated proteins, including BRCA1, BRCA2, and RAD51, in NPC cells with O6BG treatment. In addition to BRCA2 (Additional file 1: Fig. S1), O6BG reduced RAD51 expression levels in NPC cells in a concentration-dependent manner. After treatment with $4 \times \mathrm{IC}_{50}$ concentrations of O6BG $(480 \mu \mathrm{M})$ for $8 \mathrm{~h}$, RAD51 expression levels were $30 \%$ and $35 \%$ in HONE-1 and TW01 cells, respectively, compared with control cells (Fig. 1b, c). To elucidate the interlinking of MGMT and HR activity in CDDP-induced DNA damage repair, we investigated the correlation between MGMT and RAD51 expression levels in NPC cells treated with CDDP. As shown in Fig. 1d, e, Western blot analyses revealed that CDDP treatment $(10 \mu \mathrm{M})$ increased RAD51 expression levels in HONE-1 and TW01 cells, 


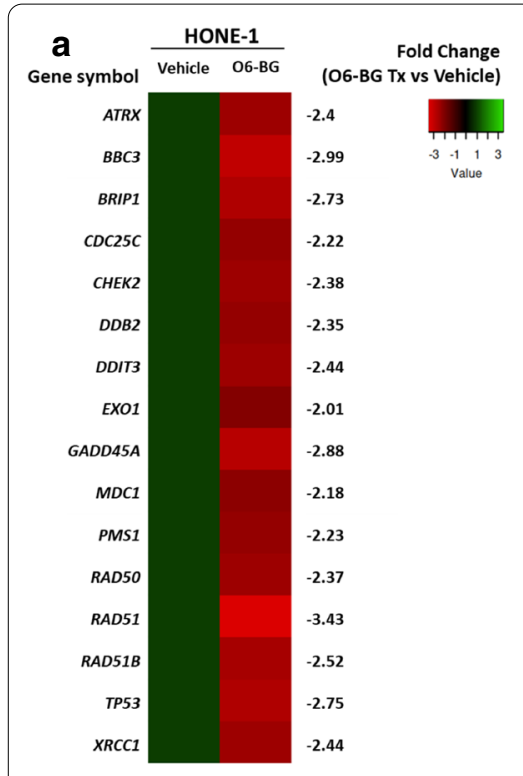

b

HONE-1

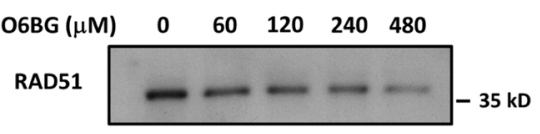

$\begin{array}{llllll}1.0 & 0.65 & 0.55 & 0.45 & 0.3\end{array}$

MGMT

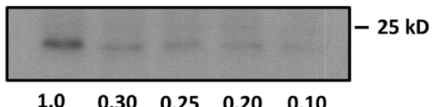

Actin

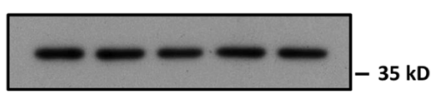

TW01

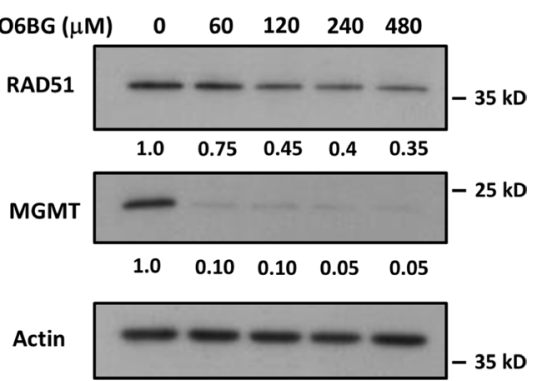

d

HONE-1
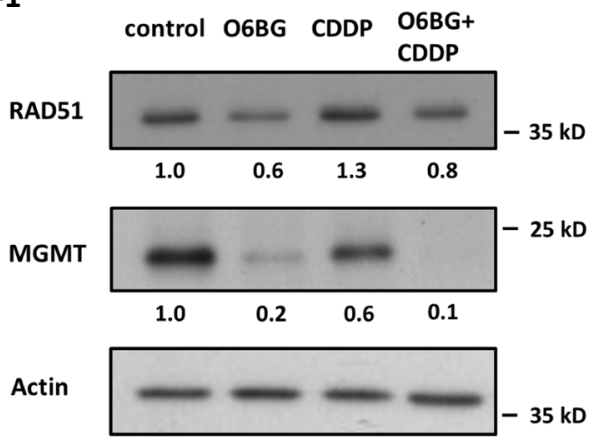

f

HONE-1

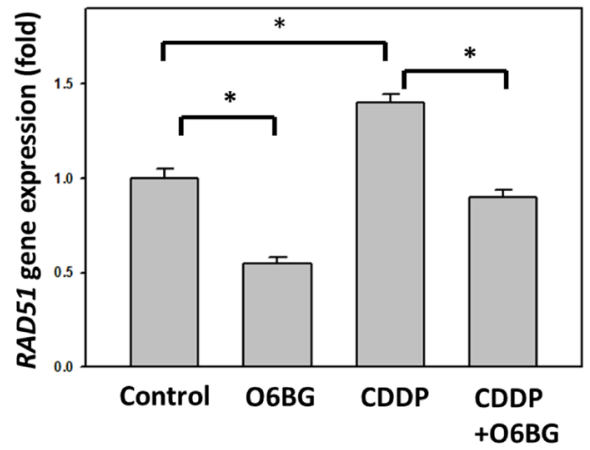

e

TW01

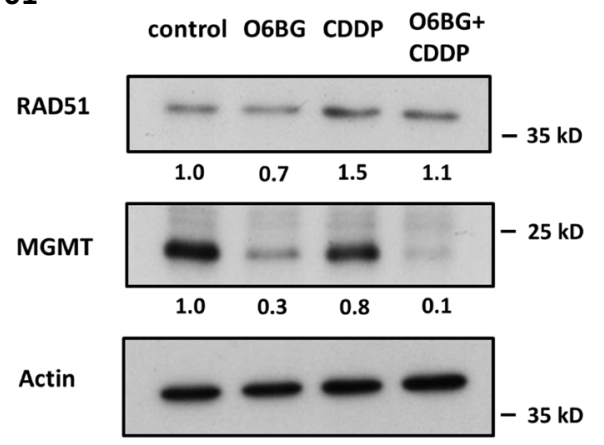

g

TW01

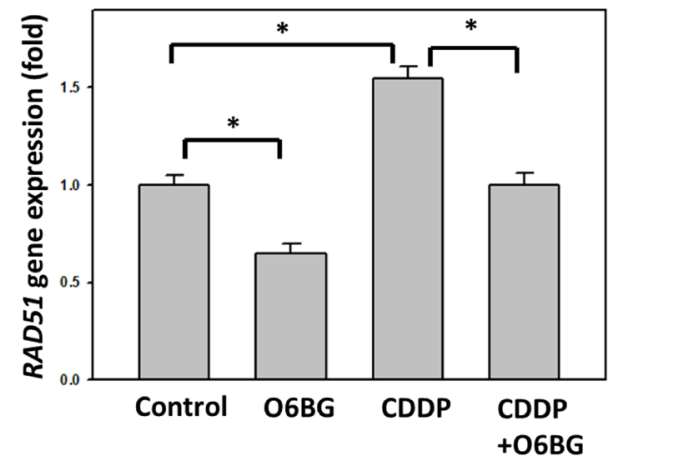

compared with control cells. However, cotreatment with O6BG (at $1 / 2$-fold of $\mathrm{IC}_{50}$ concentration) reduced CDDPinduced RAD51 expression in these two NPC cell lines.
To determine the regulatory mechanisms underlying the effects of MGMT inhibition on RAD51 expression, we examined RAD51 mRNA levels in NPC cells. RT-PCR 
(See figure on next page.)

Fig. 2 MGMT modulated CDDP-induced RAD51 expression in NPC cells. a HONE-1 and b TW01 cells transfected with scrambled or two independent MGMT-targeted siRNAs were treated with CDDP for $8 \mathrm{~h}$. Fold changes in protein levels listed under each blot were normalized to the levels of the actin control. Following treatment with CDDP as indicated in $\mathbf{a}$, $\mathbf{b}$, the mRNA levels of $\mathbf{c}$ HONE-1 and $\mathbf{d}$ TW01 cells transfected with scrambled or MGMT-targeted siRNA were quantified using qPCR. Representative results of at least three independent experiments are presented. Bar values are presented as mean \pm SD of at least three independent experiments. ${ }^{*} P<0.05$. e The correlation between MGMT and RAD51

expression levels in patients with NPC (GSE102349) was analyzed using Pearson correlation analyses. The correlation coefficient and $P$ are indicated

analyses revealed that CDDP treatment increased RAD51 mRNA levels to $140 \%$ and $155 \%$ in HONE-1 and TW01 cells, respectively, whereas O6BG treatment reduced RAD51 mRNA levels to $55 \%$ and $60 \%$ in HONE-1 and TW01 cells, respectively, compared with control cells (Fig. 1f, g). Moreover, in combination with CDDP treatment, O6BG treatment reduced RAD51 mRNA levels from $140 \%$ to $90 \%$ and $155 \%$ to $100 \%$ in HONE-1 and TW01 cells, respectively, compared with control cells. These results suggest that MGMT inhibition can suppress RAD51 expression levels in NPC cells with CDDP treatment.

To evaluate the interaction between MGMT and RAD51 further, we examined whether MGMT itself plays an active role in RAD51 expression regulation in NPC cells, especially with CDDP treatment. For this purpose, we used the siRNA technique to silence MGMT expression in NPC cells. As shown in Fig. 2a, b, Western blot analyses of our NPC cells revealed that specific-targeting siRNA transfections effectively reduced MGMT expression levels. Additionally, Western blot analyses demonstrated that RAD51 expression levels were lower in $M G M T$-deficient NPC cells treated with CDDP compared with MGMT-proficient cells (Fig. 2a, b). RT-PCR analyses also showed that RAD51 mRNA levels were decreased by $40 \%-50 \%$ and $50 \%-55 \%$, respectively, in MGMT-deficient HONE-1 and TW01 cells treated with CDDP, compared with MGMT-proficient cells (Fig. 2c, d). To evaluate the correlation between MGMT and RAD51 expression in patients with NPC, we reappraised the data deposited in one public dataset (GSE102349). An examination of gene expression levels in a total of 113 patients with NPC revealed that MGMT expression was positively correlated with $R A D 51$ expression, as shown in Fig. 2e. Taken together, these results suggest that MGMT correlates with RAD51 expression levels in NPC cells, particularly with CDDP treatment.

MGMT interacts with BRCA1 in NPC cells treated with CDDP A previous report demonstrated that MGMT physically interacts with BRCA2 in human cells [22]; however, the interactions between MGMT and other HR-associated components remain unclear. Therefore, we first used Co-IP analyses to evaluate the interaction between MGMT and BRCA2 in NPC cells, which revealed an increase in the amount of BRCA2 conjugated with antiMGMT antibodies in NPC cells treated with CDDP compared with control cells (Additional file 1: Fig. S2). Notably, after precipitation and blotting with antiMGMT and BRCA1 antibodies, respectively, we also observed the presence of MGMT-BRCA1 conjugates in NPC cells (Fig. 3a, b). Furthermore, the amounts of MGMT-BRCA1 conjugates also increased in CDDPtreated NPC cells compared with control cells. To further determine whether MGMT can interact with BRCA1 in NPC cells, we used confocal microscopy for locus detection after immunofluorescence staining. After costaining with MGMT and BRCA1, we quantitated the number of NPC cells with double-staining positivity, which were defined by more than five loci of MGMT and BRCA1 coformation in the nuclei. The immunofluorescence studies revealed that CDDP treatment increased the percentages of HONE-1 and TW01 cells with doublestaining positivity by $40 \%$ and $50 \%$, respectively (Fig. 3c, d). For the definite detection of the physical interaction between MGMT and BRCA1, we performed PLA by using anti-MGMT and anti-BRCA1 antibodies as probes in HONE-1 cells. In this immunohistochemical tool that allows in situ detection of endogenous proteins, we found that PLA-positive signals were increased in NPC cells with CDDP treatment (Fig. 3e). These results all indicate that MGMT can physically interact with BRCA1 in NPC cells, especially with CDDP treatment.

Phosphorylation of BRCA1-specific residues is a critical step for DNA repair function of this protein. Among these specific residues, previous reports have demonstrated that phosphorylation of ser 988 on BRCA1 is involved in HR activation $[29,30]$. To explore the biological significance of the crosstalk between MGMT and BRCA1, we examined the expression levels of this specific residue phosphorylation (ser 988) on BRCA1 in NPC cells. As shown in Fig. 3f, CDDP treatment increased the expression levels of ser 988 phosphorylation on BRCA1 in the nuclei of HONE-1 cells; by contrast, O6BG treatment reduced the expression levels of CDDP-induced ser 988 phosphoprotein in HONE-1 cells. After transfection with siRNA targeting MGMT, the expression levels of ser 988 phosphorylation on BRCA1 were also lower in MGMT-deficient cells treated with CDDP compared with MGMT-proficient cells (Fig. 3g). Accordingly, these 


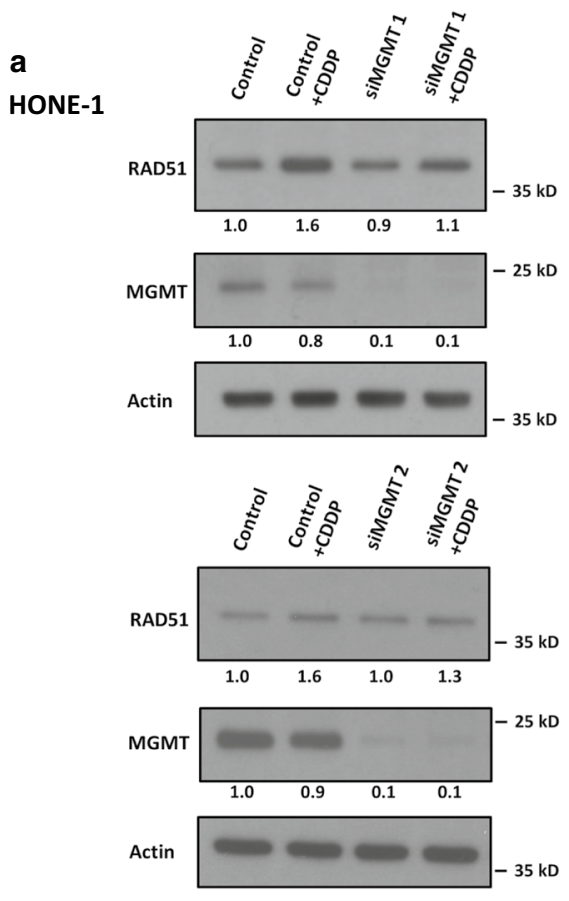

\section{HONE-1}
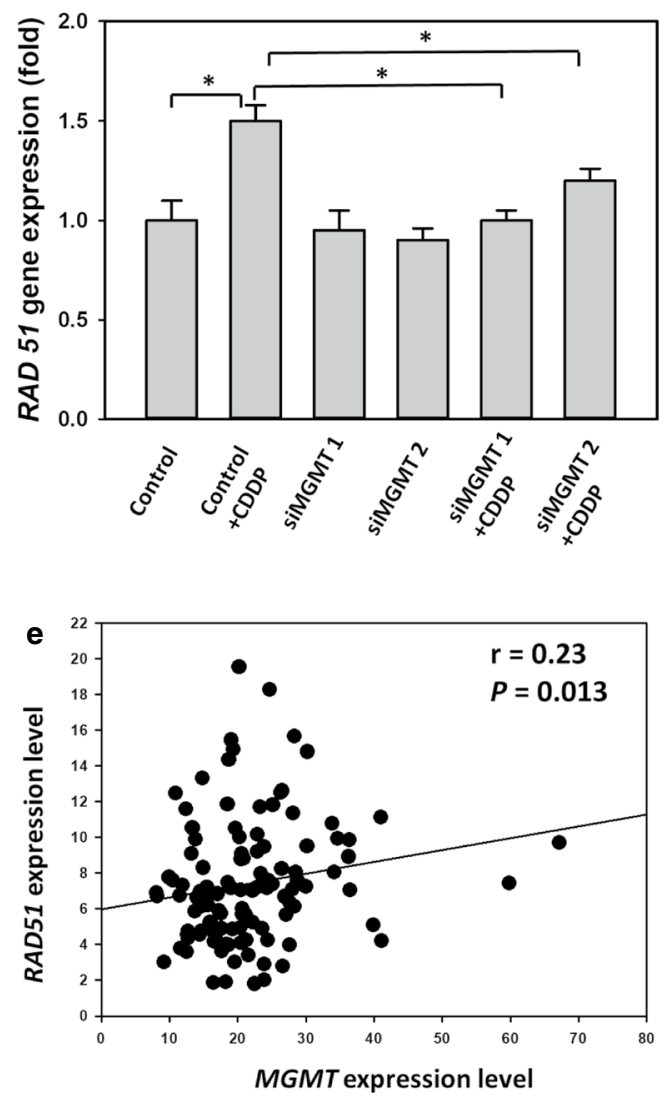

b

TW01
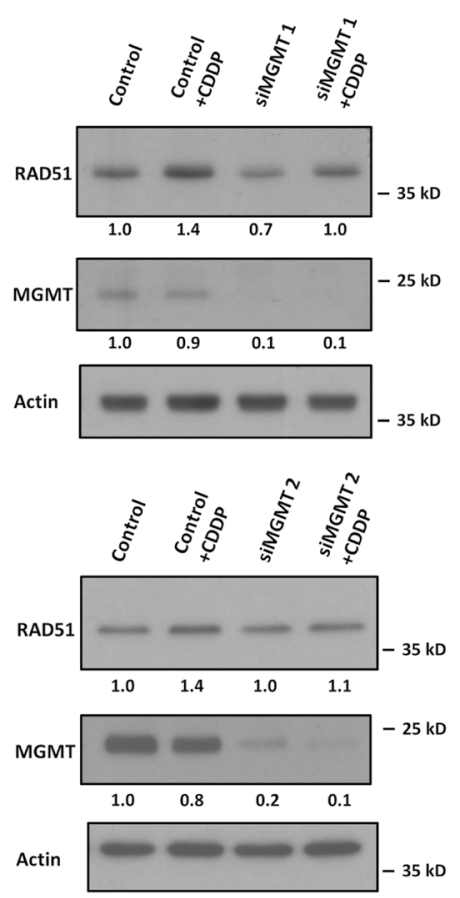

d TW01

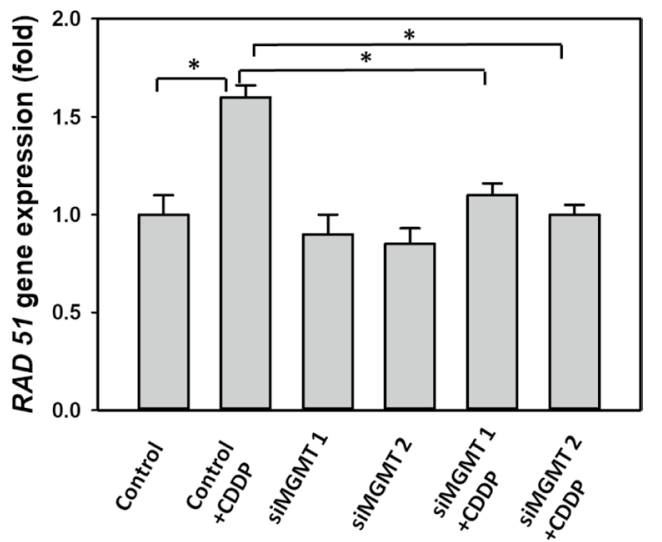




\begin{abstract}
(See figure on next page.)
Fig. 3 MGMT interacted with BRCA1 in NPC cells with CDDP treatment. After treatment with or without $10 \mu \mathrm{M}$ CDDP for $8 \mathrm{~h}$, the protein lysates of $\mathbf{a}$ HONE-1 and $\mathbf{b}$ TW01 cells were subjected to Co-IP analyses with $1 \mu \mathrm{g} / \mathrm{mL}$ anti-MGMT antibodies followed by Western blotting. Following the indicated treatment as in $\mathbf{a}$ and $\mathbf{b}$, representative immunofluorescence images of DAPI, MGMT, and BRCA1 in $\mathbf{c}$ HONE-1 and d TW01 cells were processed through confocal microscopy. At least 200 cells were subjected to each treatment in each experiment. The bar graph (right panel) shows the percentage of tested cells containing five or more colocalizing foci for the staining proteins. Bar values are presented as mean \pm SD of at least three independent experiments. ${ }^{*} P<0.05$. e Endogenous physical interactions between MGMT and BRCA1 proteins were detected by using in situ PLA in HONE-1 cells with or without CDDP treatment (10 $\mu \mathrm{M}$ for $8 \mathrm{~h}$ ). PLA-positive signals are indicated by red fluorescent puncta and visualized by fluorescence microscopy. DAPI was used to detect the nuclei. To examine nuclear proteins, HONE-1 cells were initially $\mathbf{f}$ treated with $\mathrm{O} 6 \mathrm{BG}(60 \mu \mathrm{M})$ or $\mathbf{g}$ transfected with MGMT-targeted siRNA. Following CDDP treatment as indicated in a, nuclear protein lysates were extracted and subjected to Western blot analyses with anti-pRBCA1, BRCA1 and MGMT antibodies. Fold changes in protein levels listed under each blot were normalized to the levels of the actin control. Representative results of at least three independent experiments are shown. Scale bars indicate $10 \mu \mathrm{m}$
\end{abstract}

findings suggest that MGMT suppression can disturb ser 988 phosphorylation on BRCA1 in NPC cells treated with CDDP.

\section{MGMT inhibition enhances CDDP-induced DNA damage and impairs HR activity in NPC cells}

Because we found that MGMT is involved in RAD51 expression and BRCA1 phosphorylation in NPC cells treated with CDDP, we assessed whether MGMT expression can modulate CDDP-induced DSBs in NPC cells. To this end, we first performed a neutral comet assay to measure DSB formation in NPC cells. By measuring the tail movement of each cell, the comet assays demonstrated that O6BG treatment increased CDDP-induced DSB levels by $30 \%$ and $25 \%$ in HONE- 1 and TW01 cells, respectively, compared with those with CDDP treatment alone (Fig. 4a, b). Moreover, combination treatment significantly increased the expression levels of $\gamma-\mathrm{H} 2 \mathrm{AX}$, a marker indicating DNA DSBs, compared with treatment with O6BG or CDDP alone (Fig. 4c, d). After pertinent siRNA transfection, the expression levels of $\gamma-\mathrm{H} 2 \mathrm{AX}$ induced by CDDP treatment were increased in MGMTdeficient NPC cells compared with MGMT-proficient cells (Fig. 4e, f). All these findings suggest that MGMT can mediate CDDP-induced DSBs in NPC cells.

To elucidate whether MGMT can modulate CDDPinduced DSBs in NPC cells by targeting HR repair activity, we analyzed the interaction between $\gamma$ - $\mathrm{H} 2 \mathrm{AX}$ and RAD51 through immunofluorescent staining, as described previously [27]. The results were comparable to those displayed in Fig. 4c, d; combination treatment with O6BG and CDDP increased the percentages of $\gamma$-H2AX-positive HONE-1 and TW01 cells, which contained more than five loci in the nucleus, by $25 \%$ and $20 \%$, respectively, compared with CDDP treatment alone (Fig. 5a-c). Notably, through quantification of RAD51 recruitment in $\gamma$-H2AX-positive cells, combination treatment reduced HR repair activity by $25 \%$ and $30 \%$ in HONE-1 and TW01 cells, respectively, compared with
CDDP treatment alone (Fig. 5c). In MGMT-deficient cells by using specific targeting siRNA, the percentages of $\gamma$-H2AX-positive cells were increased by $40 \%$, whereas the percentages of cells with RAD51 recruitment in DNA damage site were decreased by $40 \%$ (Fig. $5 \mathrm{~d}$, e). These results suggest that MGMT suppression can attenuate CDDP-induced HR activity in NPC cells. We further assessed HR repair activity by using an in vivo plasmid recombination-based method. As shown in Fig. 5f, O6BG treatment reduced HR repair function in NPC cells in a dose-dependent manner. When treated with O6BG at a concentration of $120 \mu \mathrm{M}$, the HR activity levels were decreased by $26 \%$ and $33 \%$ in HONE- 1 and TW01 cells, respectively, compared with control cells. Furthermore, HR activity was reduced by $10 \%$ and $15 \%$ in HONE- 1 and TW01 cells after transfection with siRNA targeting MGMT compared with nontargeted control cells (Fig. 5g). Collectively, these results indicate that MGMT downregulation can enhance CDDP-induced DSBs and attenuate HR activity in NPC cells.

\section{Combination treatment with CDDP and MGMT inhibitor delays tumor growth in NPC xenografts}

Because of the potential effectiveness of combination treatment with O6BG and CDDP reported in in vitro studies, we conducted tumor xenograft studies for further evaluation. We subcutaneously implanted HONE-1 cells in the flank of nude mice, and each treatment started when the tumor volume became palpable. Study xenografts were allocated to four treatment arms: vehicle control, daily O6BG injection, twice-weekly CDDP injection, and combination treatment with O6BG and CDDP. On treatment day 21 , the tumor volume increased by $17.5-$, 13.7-, 12-, and 7.5-fold in the vehicle, O6BG, CDDP, and combination treatment groups, respectively. The tumor volumes at the end of this xenograft study were significantly decreased in combination treatment group, compared with any other treatment (all $P<0.05$; Fig. 6a). No significant changes in body weights were observed 


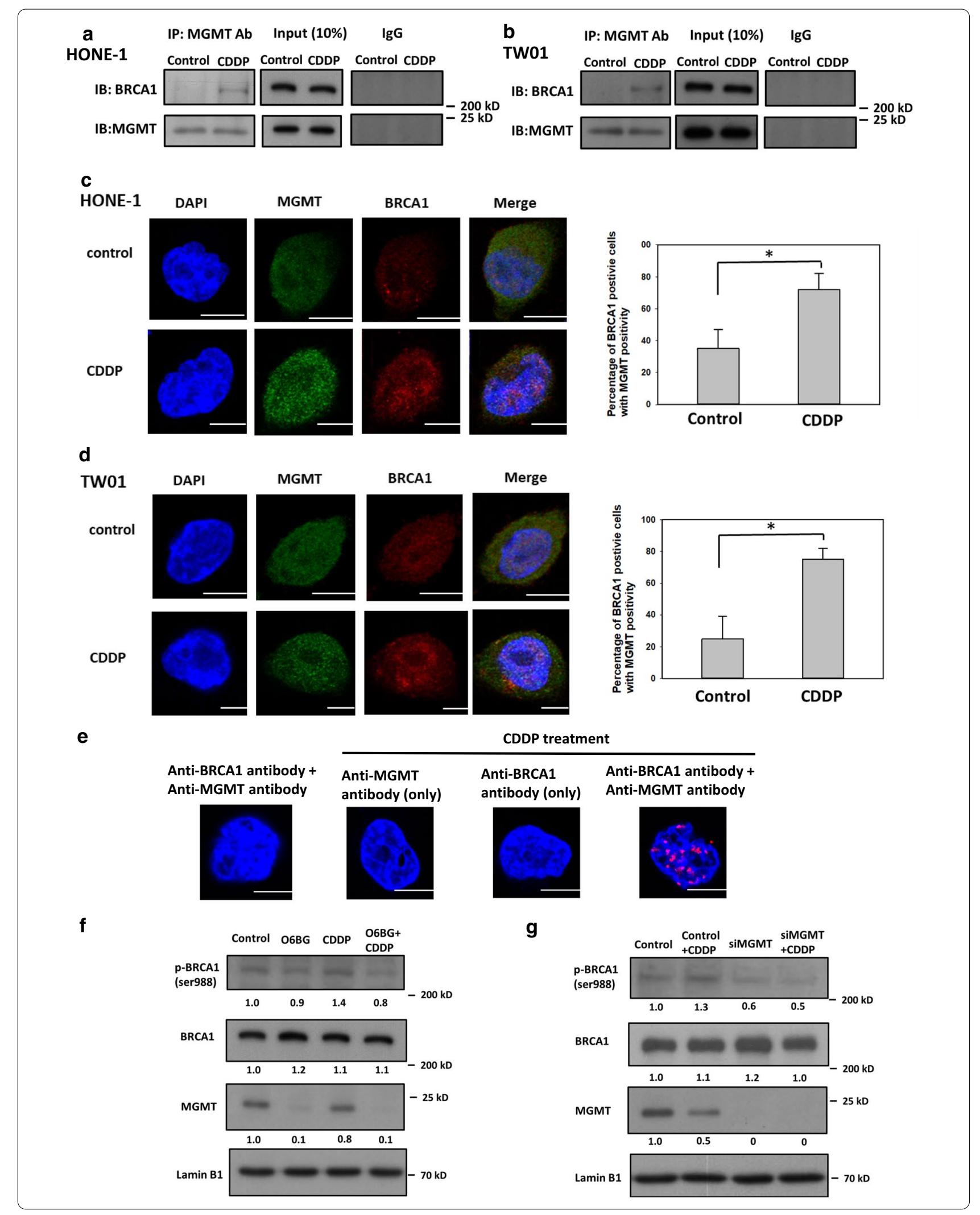


(See figure on next page.)

Fig. 4 MGMT inhibition enhanced CDDP-induced DSB in NPC cells. After treatment with O6BG (60 $\mu \mathrm{M})$, CDDP alone or a combination of both for $24 \mathrm{~h}$, the DSB formation of $\mathbf{a}$ HONE-1 and $\mathbf{b}$ TW01 cells were analyzed using the neutral comet assay. After electrophoresis, the cell slides were stained with PI for visualization. The percentages of DNA in the tail were quantified by measuring the proportion of tail length in at least 100 comet cells and are presented as bar histograms. Bar values are presented as mean \pm SD of at least three independent experiments. ${ }^{*} P<0.05$. The expression of $\mathrm{\gamma}-\mathrm{H} 2 \mathrm{AX}$ was examined using Western blot analyses in $\mathbf{c} \mathrm{HONE}-1$ and $\mathbf{d}$ TW01 cells following treatment with O6BG (60 $\mu \mathrm{M})$, CDDP $(10 \mu \mathrm{M})$, or a combination of both for $24 \mathrm{~h}$. The expression of $\mathrm{Y}-\mathrm{H} 2 \mathrm{AX}$ induced by CDDP treatment was also examined in MGMT-proficient or -deficient NPC cells. After e HONE-1 and f TW01 cells were transfected with scrambled or MGMT-targeted siRNA for $24 \mathrm{~h}$, these cells were treated with CDDP for another $24 \mathrm{~h}$. Representative images of at least three independent experiments are shown

between mice receiving each treatment (Fig. 6b). The sizes of tumors dissected from sacrificed mice subjected to combination treatment were also significantly smaller than those of tumors in other treatment groups (Fig. 6c).

To assess alterations of HR components induced by O6BG in vitro, we examined the expression levels of RAD51and BRCA1 phosphorylation (ser 988) in tumors through IHC staining. Compared with control mice, RAD51 expression levels were significantly decreased in O6BG-treated tumors (Fig. 6d). Furthermore, in tumors subjected to combination treatment, the expression levels of RAD51 and BRCA1 phosphorylation were lower than those in tumors treated with CDDP alone. Taken together, these results support that MGMT inhibition can reduce CDDP-induced expression of RAD51 and BRCA1 phosphorylation in NPC cells. Further, combination treatment with MGMT inhibitor and CDDP can be efficacious against the growth of NPC cells.

\section{MGMT suppression enhances olaparib-induced cytotoxicity in NPC cells}

Tumors harboring defects in the HR system is highly vulnerable to the cytotoxic effects of poly(ADP-ribose) polymerase (PARP) inhibitors [12, 13], and we investigated whether MGMT inhibition can increase the cytotoxicity of PARP inhibitors in NPC cells. After suppression of MGMT expression through the addition of O6BG for $8 \mathrm{~h}$, the $\mathrm{IC}_{50}$ values of olaparib, the first PARP inhibitor in clinical use, were decreased by approximately $50 \%$ in both HONE-1 and TW01 cells (Table 1). The clonogenic assays also showed that the addition of O6BG enhanced the cytotoxicity of olaparib in NPC cells (Fig. 7a, b). After cotreatment with O6BG and olaparib, the numbers of forming colonies decreased by $22 \%$ and $27 \%$ in HONE-1 and TW01 cells, respectively, compared with treatment with olaparib alone. To further assess the cytotoxic effects of olaparib treatment in NPC cells with MGMT inhibition, we detected the percentages of apoptotic cells through FACS-based annexin V/PI double-staining. The flow cytometry analyses demonstrated that combination treatment with O6BG and olaparib increased the populations of apoptotic cells (annexin V-positive cells) by $13 \%$ and $19 \%$ in HONE-1 and TW01 cells, respectively, compared with treatment with olaparib alone (Fig. 7c, d). In addition, the expression levels of $\gamma$-H2AX were significantly increased in NPC cells treated with a combination of O6BG and olaparib compared with those treated with olaplarib alone (Fig. 7e, f). These results suggest that MGMT inhibition can enhance olaparib-induced cytotoxicity and DSBs in NPC cells.

To further examine whether MGMT expression levels mediated the anticancer effects of olaparib in NPC cells, the cytotoxicity tests of olaparib were conducted in TW01 cells with MGMT-targeted siRNA transfection. As shown in Additional file 1: Fig. S3a and b, the survival rates of MGMT-deficient TW01 cells treated with olaparib were decreased by $23 \%$, whereas the populations of apoptotic cells were increased by $25 \%$, compared with scrambled control. Western blot analyses also showed that olaparib treatment increased the expression levels of $\gamma$-H2AX in MGMT-deficient TW01 cells (Additional file 1: Fig. S3c). Collectively, our data indicate that MGMT expression levels modulate the cytotoxicity of PARP inhibitor in NPC cells.

\section{Discussion}

Since the development of CDDP in the 1970s, this platinum-based chemotherapy drug has shown promising anticancer efficacy in a variety of cancers, including NPC. In addition to monotherapy, combination treatment with CDDP and other anticancer therapies, such as radiotherapy and other chemotherapy drugs, is also a common therapeutic strategy in cancer patients because of its synergistic effect against tumor growth $[8,9]$. Even with the advances in immunotherapy, combination treatment with CDDP and an immune checkpoint inhibitor has demonstrated survival benefits in patients with a certain type of cancer, including head and neck cancer $[8,31$, 32]. Accordingly, several researchers have devoted their research to overcoming CDDP resistance for decades. Currently, it is believed that CDDP resistance can be 


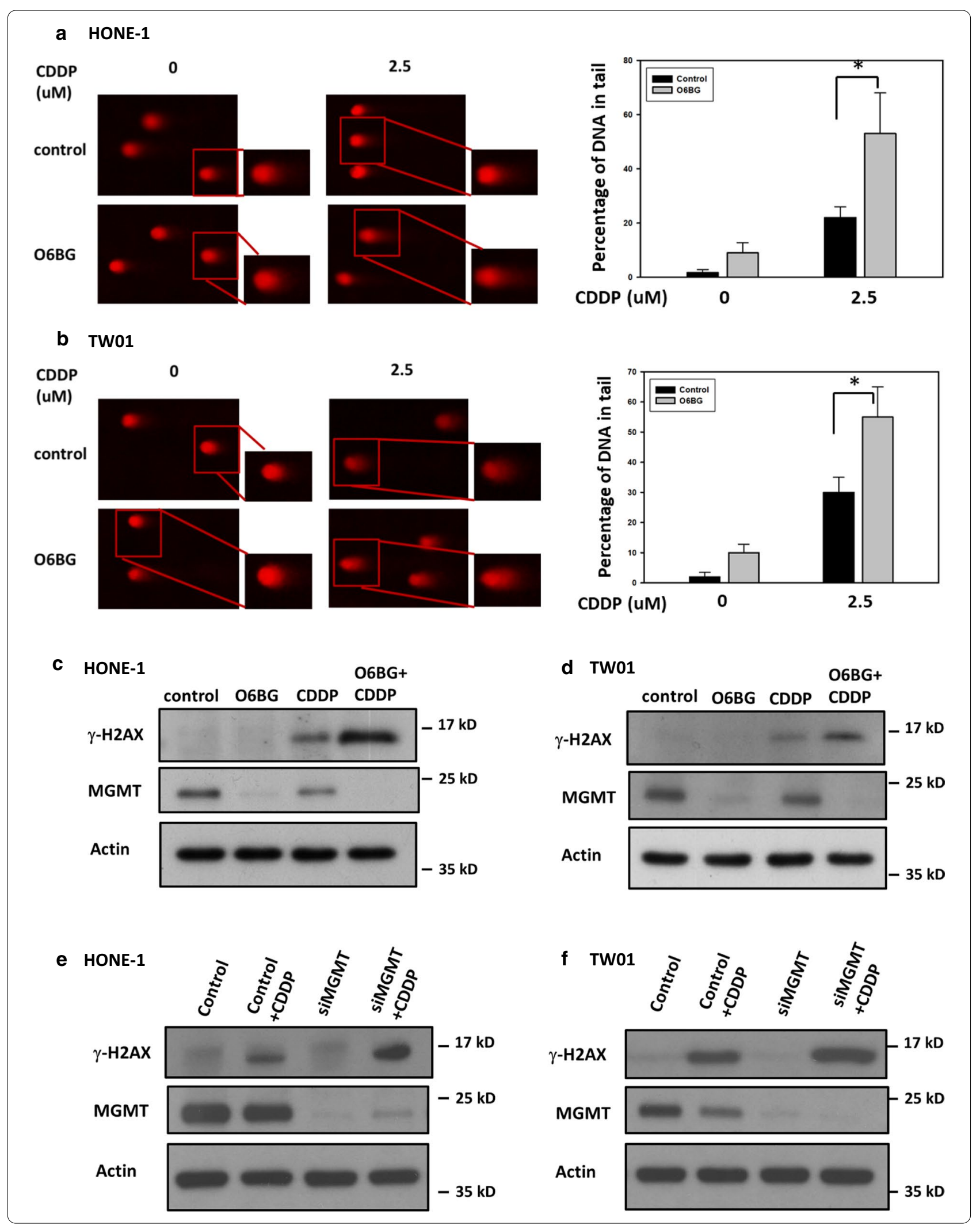




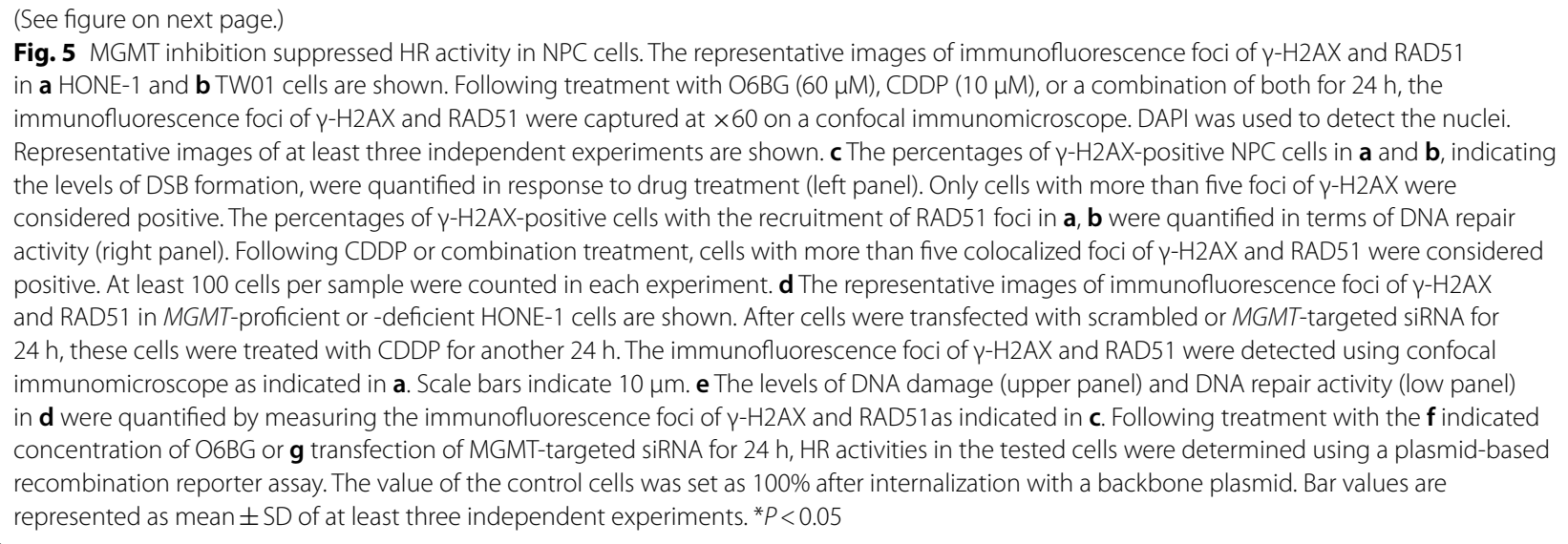

regulated by numerous intracellular (e.g., ion transporters, detoxification enzymes, and DNA repair pathway) and extracellular (e.g., hypoxia, acidity, and immunosuppressive cells) factors. Because the main cytotoxic effects of CDDP are generated from DNA damage in cancer cells, studies focusing on the action mechanisms of DDR in the regulation of CDDP resistance are compelling for most investigators. In fact, several reports have shown that platinum-DNA adducts can majorly be repaired by the activation of NER pathway [10]. If left unrepaired, the DNA damage caused by these bulky DNA adducts can progress to DSB formation, the repair of which is performed by the activation HR pathway [11]. Because genomic instability is a central part of tumor progression [33], the network of CDDP-induced DDR, which is composed of miscellaneous types of DNA pathways, is certainly intricate and entangled in cancer cells. Among various DNA repair pathways, MGMT is a unique DNA repair enzyme that repairs alkylating groups on the $\mathrm{O} 6$ position of guanine [17]. This DNA repair enzyme can repair O6-alkylguanines without the involvement of other repair proteins and undergo ubiquitination-mediated degradation after the repair process is completed. Although the action mechanisms remain unclear, several studies have reported that MGMT expression is correlated with CDDP cytotoxicity in cancer cells [34-36]. In our previous study, we have shown that MGMT can enhance the DNA repair activity for platinum-DNA adducts in NPC cells [18]. Furthermore, Philip and his colleagues have reported that MGMT is physically involved in BRCA2-containing molecular complexes in cancer cells [22]. Based on these results, we hypothesize that MGMT can modulate CDDP-induced DDR by targeting the HR pathway. In the present study involving several functional assays, xenograft studies, and data mining of a public database, we demonstrated that MGMT participated in the HR signaling pathway and affected CDDP and PRAP inhibitor cytotoxicity in NPC cells.

The HR signaling pathway has attracted considerable interest in cancer research because of the high cancer susceptibility arising from genomic mutations of its component proteins [30,33]. This repair process involves initial damage recognition by the ataxia-telangiectasia mutated and ataxia telangiectasia and Rad3related kinase; signal mediation by CHK2, BRCA1, and BRCA2; and final repair by the effector RAD51. Therefore, the function of RAD51 is critical to the HR repair efficiency and is correlated with CDDP resistance in cancer cells [37-40]. In the present study, we found that RAD51 expression levels were increased in NPC cells treated with CDDP, thus evidencing its important role in the repair of CDDP-induced DNA damage (Figs. 1, 2). Moreover, our study revealed that MGMT suppression by a specific inhibitor or the siRNA technique reduced CDDP-mediated RAD51 expression in NPC cells, comparable to the positive correlation data between MGMT and RAD51 expression levels observed in a cohort of NPC patients (GSE102349). These results suggest that MGMT interacts with RAD51 expression in NPC cells, particularly after CDDP treatment. Because O6BG treatment inhibits MGMT expression through the ubiquitin-proteasome degradation pathway [17], some unknown biological effects may be involved in this process of MGMT inhibition. Therefore, prominent RAD51 downregulation may be induced in NPC cells with O6BG treatment compared with those with siRNA transfection in the present study. In addition to RAD51, BRCA1 is essential to the signaling transduction of the HR pathway. Several reports have also demonstrated that patients with 


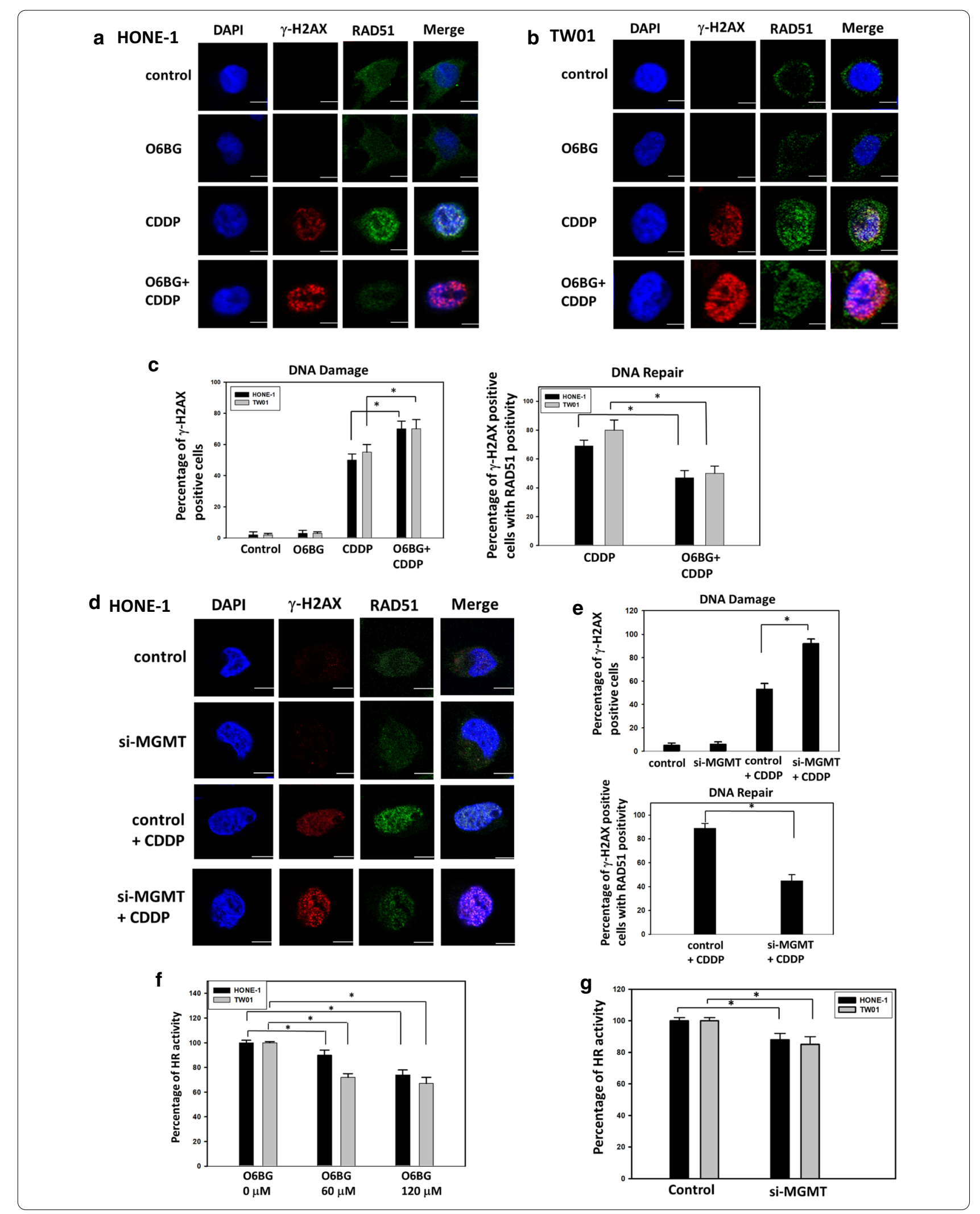


(See figure on next page.)

Fig. 6 MGMT inhibition with CDDP treatment retarded NPC tumor growth. a Tumor volume and $\mathbf{b}$ body weight in mice bearing tumors were measured twice weekly. Tumor mass was measured with a caliper and calculated as $\pi / 6 \times$ length $(\mathrm{mm}) \times$ width $(\mathrm{mm})^{2}$. c After 21 days of treatment, the mice were sacrificed, and tumor sizes were measured. The average tumor sizes in each treatment group are presented as a bar histogram (right panel). Bar values are presented as mean $\pm S D .{ }^{*} P<0.05$. $\mathbf{d}$ The expression of MGMT, RAD51, and $\mathrm{p}-\mathrm{BRCA} 1$ was analyzed in paraffin-embedded tumor sections obtained from mice in each treatment group through immnunohistochemical staining. The slides were then examined under a fluorescence microscope, and photomicrographs were taken at a magnification of $\times 400$

cancer frequently carrying $B R C A 1$ mutation are susceptible to CDDP treatment [41-44]. In addition to BRCA2, Co-IP, confocal immunofluorescence microscopy analyses and PLA studies revealed the physical interaction between MGMT and BRCA1 in NPC cells in the present study (Fig. 3). Interestingly, CDDP treatment significantly increased the amounts of immune complexes containing both MGMT and BRCA1 in NPC cells, also suggesting a role of MGMT in the CDDP-induced HR pathway. To further explore the biological significance of the interaction between MGMT and BRCA1, we examined whether MGMT can mediate BRCA1 phosphorylation (ser 988) in HONE-1 cells treated with CDDP. As noted, BRCA1 engages in the signaling transduction of the HR pathway mainly through the phosphorylation of its specific residues [29, 30]. The phosphorylation of ser 988 on BRCA1 mediated by CHK2 activation is required for the recruitment of RAD51 to the DNA damaged site. As expected, we found that CDDP treatment enhanced the expression levels of p-BRCA1 (ser 988) in the nucleus of HONE-1 cells, indicating its important role in the CDDP-mediated HR signaling pathway (Fig. 3). Additionally, we found that MGMT suppression (through O6BG treatment and the siRNA technique) abrogated CDDP-induced p-BRCA1 expression in HONE-1 cells. These results also indicate that MGMT is involved in BRCA1 signaling transduction of the HR pathway activated by CDDP treatment. In our previous study, we observed that MGMT proteins were present in nucleic acids containing platinum adducts [18]. Taken together, these results support the participation of MGMT in the signaling transduction of HR pathway induced by CDDP in NPC cells.

Because the main function of the HR pathway is DNA DSB repair, we subsequently investigated whether MGMT can determine CDDP-induced DSB formation in NPC cells. The neutral comet assay, an established technique for quantifying DSBs by measuring the tail length of a cell, was first used in our functional studies [41]. In this electrophoresis-based assay, cotreatment with O6BG and CDDP increased the tail lengths of NPC cells compared with CDDP treatment alone (Fig. 4). Comparably, CDDP-induced expression levels of $\gamma$-H2AX, a sensitive marker for DSB formation, were increased in
O6BG-treated NPC cells. These results all suggest that MGMT is associated with CDDP-induced DSB regulation in NPC cells through the HR pathway. Therefore, we directly evaluated the efficiency of the HR pathway in repairing CDDP-induced DNA damage by using two established functional assays. One was an immunofluorescence-based study that considers the HR pathway to be activated if more than five colocalization foci of RAD51 and $\gamma$-H2AX immune signal are detected in the nucleus of the NPC cell [27]. The other was a reporter plasmid-based assay, which can measure HR activity by calculating the PCR product generated by this repair pathway [42]. In immunofluorescence-based studies, we found that cotreatment with O6BG and CDDP reduced the numbers of NPC cells with active HR signaling compared with CDDP treatment alone; in plasmid-based studies, MGMT suppression reduced the number of genomic products induced by the HR pathway (Fig. 5). Taken together, MGMT plays an active role in the HR signaling pathway responsible for the repair of CDDPinduced DNA damage in NPC cells.

MGMT is considered a perspective target in cancer therapy because of its important role in the protection of genomic damage from alkylating agents. Several therapeutic approaches have been pursued to inhibit MGMT expression in tumors, such as the utility of its pseudosubstrates, gene therapies, and viral proteins $[17,43]$. The clinical efficacy of alkylating chemotherapy drugs in combination with specific MGMT inhibitor, such as O6BG, has been demonstrated in several trials [44-47]. In our xenograft study, combination treatment with O6BG and CDDP delayed NPC tumor growth compared with CDDP alone. Moreover, O6BG abolished CDDP-activated RAD51 and p-BRCA1 expression in tumor specimens (Fig. 6). These data support the participation of MGMT in the HR pathway and the therapeutic potential of O6BG when used in combination with CDDP. Although severe hematologic toxicities have been reported in clinical trials investigating the efficacy of combination treatment with O6BG and alkylating drugs, it is likely contributed by low MGMT expression levels in hematopoietic progenitor cells $[17,43]$. However, the major toxicity caused by CDDP treatment is nephrotoxicity, and this treatment 

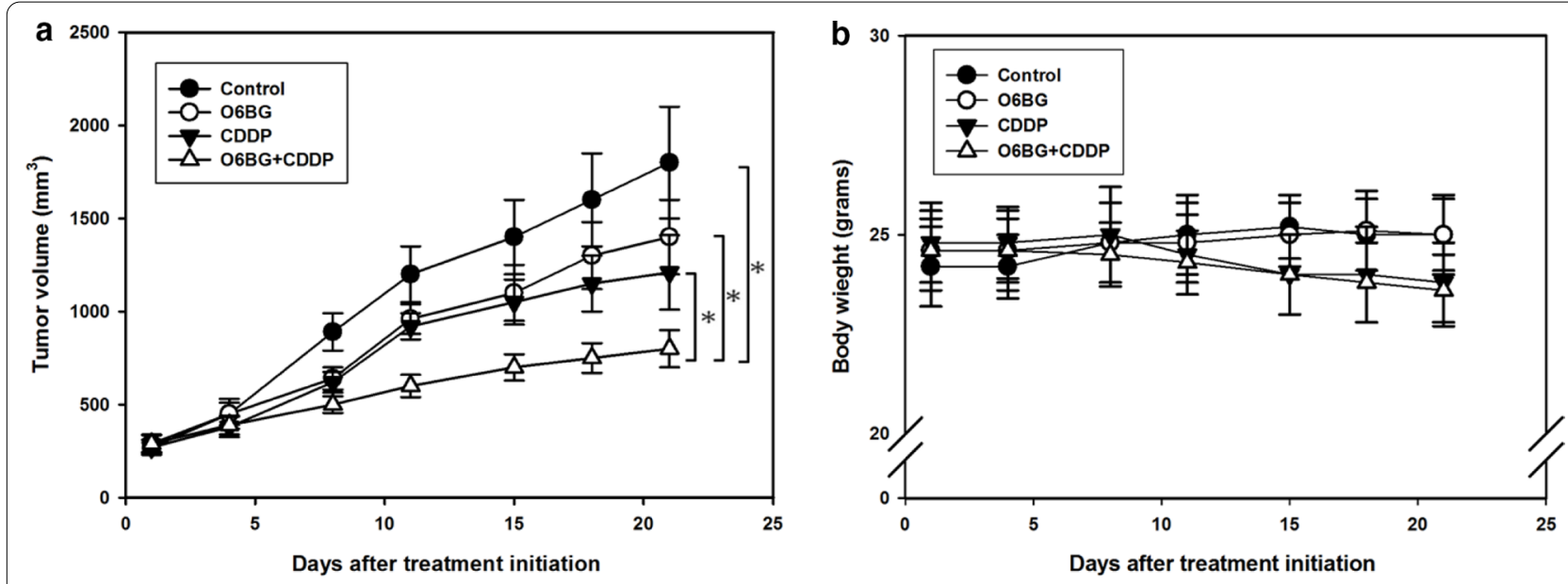

c
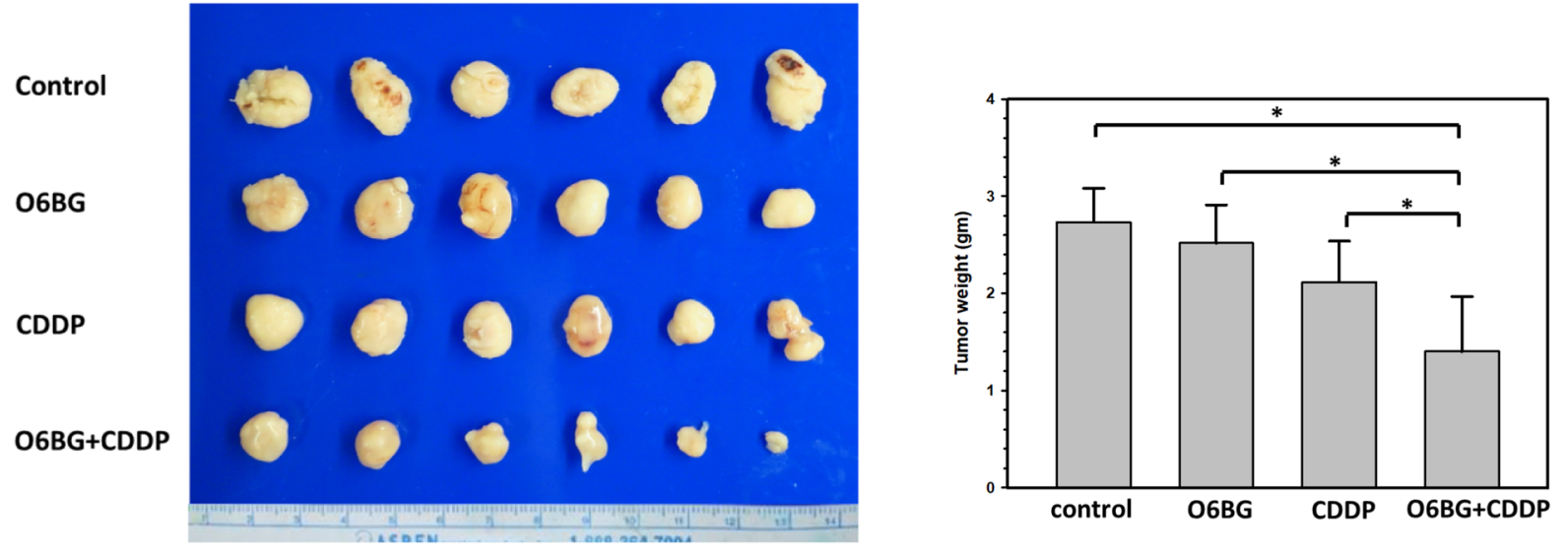

d

Control

O6BG

CDDP

O6BG+CDDP

MGMT
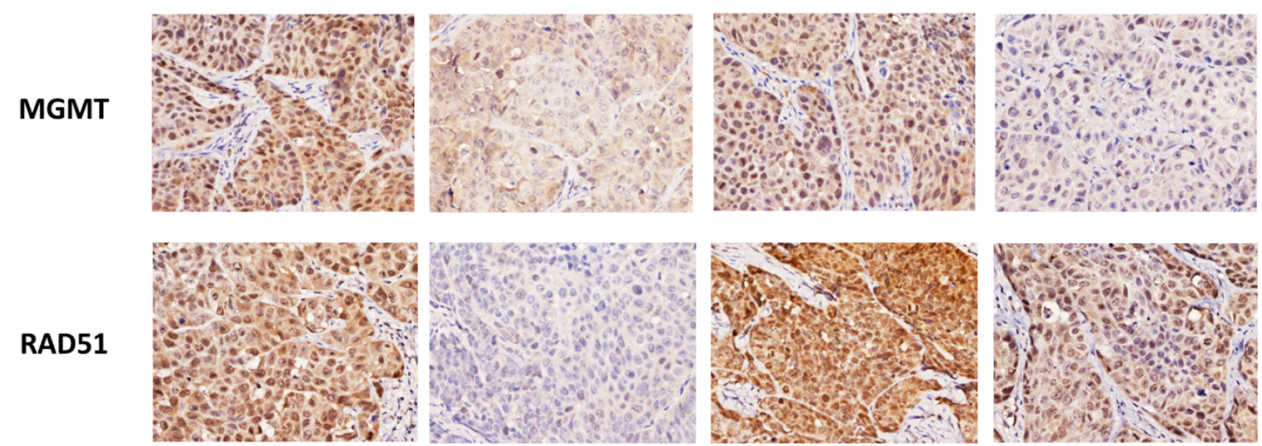

p-BRCA1
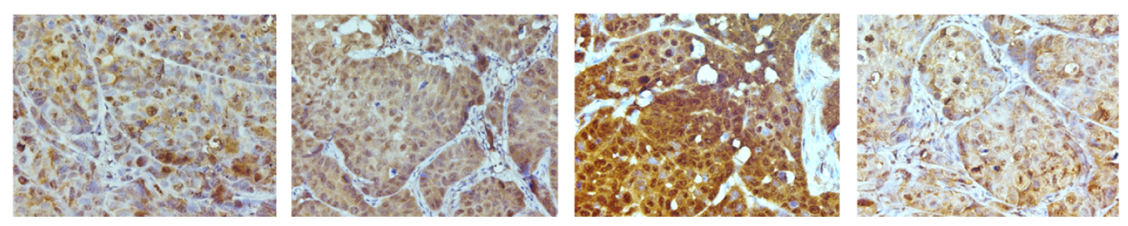
Table 1 IC $_{50}$ values of olaparib in NPC cells

\begin{tabular}{lcc}
\hline & HONE-1 $(\boldsymbol{\mu M})$ & TW01 $(\boldsymbol{\mu M})$ \\
\hline Control & $10.5 \pm 0.5$ & $122.2 \pm 8.2$ \\
O6BG & $5.2 \pm 0.4$ & $61.5 \pm 10.8$
\end{tabular}

$\mathrm{IC}_{50}$ values of olaparib were determined using a cell viability assay. Cells in the exponential phase were first treated with O6BG $(120 \mu \mathrm{M})$ for $8 \mathrm{~h}$. After medium removal and cell washing, serial concentrations of olaparib were added for three generation times. Values are presented as means \pm SDs of at least three independent experiments

causes less hematological toxicity than treatment with other alkylating chemotherapy drugs [48]. Moreover, MGMT expression is typically higher in human liver, lung, and kidney tissues [17, 49]. Consequently, studies evaluating the clinical benefits of O6BG in combination with CDDP treatment in NPC patients are encouraged.

The HR pathway has become an emerging therapeutic target because of the successful development of PARP inhibition in cancer treatments [12, 13]. Based on the concept "synthetic lethality", PARP inhibition can selectively lead to the death of BRCA1- or BRCA2-dysfunction cancer cells in which HR activity is deficient. The main function of PARP proteins is the recognition of SSB formation, and their specific inhibitors can trap these proteins on the DNA damaged site. When the replication machinery encounters these trapped proteins, the replication fork collapses with the formation of DNA DSBs. Accordingly, HRdeficient (HRD) tumor cells are highly sensitive to PARP inhibitors because of their incapability of efficiently repairing the excess formation of DNA DSB. Olaparib is the first PARP inhibitor in clinical use and is currently approved for use in the treatment of $B R C A$-mutated advanced ovarian, breast, pancreatic, and prostate cancers. Because MGMT inhibition attenuated $\mathrm{HR}$ activity, we tested the cytotoxic effects of a combination of O6BG and olaparib in the present study. Our functional assays revealed that O6BG increased olaparib-induced DSB formation and cell apoptosis in NPC cells, supporting the therapeutic strategy of combining MGMT and PARP inhibitor in treating cancer patients. Furthermore, in the modern era of precision medicine, identifying the most susceptible patients using predictive companion diagnostics is helpful to maximize the clinical benefit of a specific anticancer therapy. With the advances in the genomic sequencing technique, diagnostic approaches to recognizing HRD tumors have been developed for treatment response prediction of both CDDP and PARP inhibitors [50-52]. The regulation mechanisms of $M G M T$ expression through its promoter methylation status have been well explored in patients with glioblastoma $[17,43]$. In our previous study, we demonstrated that methylation modification of the MGMT promoter region by using high-throughput sequencing is also correlated with MGMT expression in NPC tumors [18]. Thus, the examination of the MGMT promoter methylation in gene signatures for identifying HRD tumors is notable.

\section{Conclusion}

We demonstrated that MGMT is involved in RAD51 expression and BRCA1 phosphorylation in NPC cells (Fig. 8). By attenuating HR activity, the MGMT suppression enhanced DSB formation and cell death induced by CDDP or PARP inhibitor. These results suggest that MGMT is a potential therapeutic and diagnostic target in cancer treatment with CDDP or PARP inhibitor.

\footnotetext{
(See figure on next page.)

Fig. 7 MGMT inhibition increased the cytotoxicity of PARP inhibitor in NPC cells. The survival rates of a HONE-1 and $\mathbf{b}$ TW01 cells were examined using the clonogenic assay. The percentages of apoptotic cells in $\mathbf{c} H O N E-1$ and $\mathbf{d}$ TW01 cell samples were analyzed through flow cytometry after costaining the cells with FITC-conjugated annexin $\mathrm{V}$ and PI. The $\mathrm{\gamma}$-H2AX expression of e HONE-1 and $\mathbf{f}$ TW01 cells was investigated using Western blot analyses. Representative histograms indicated the percentages of colony formation and apoptosis cells (annexin $V$-positive cells). The tested cells were exposed to O6BG $(60 \mu \mathrm{M})$, olaparib at indicated concentrations or combination treatment for $24 \mathrm{~h}$, and then analyzed for colony formation, apoptotic cell proportion, and $\mathrm{y}-\mathrm{H} 2 \mathrm{AX}$ expression. Experiments were performed at least three times. Bar values are presented as mean $\pm \mathrm{SD}$. ${ }^{*} P<0.05$
} 

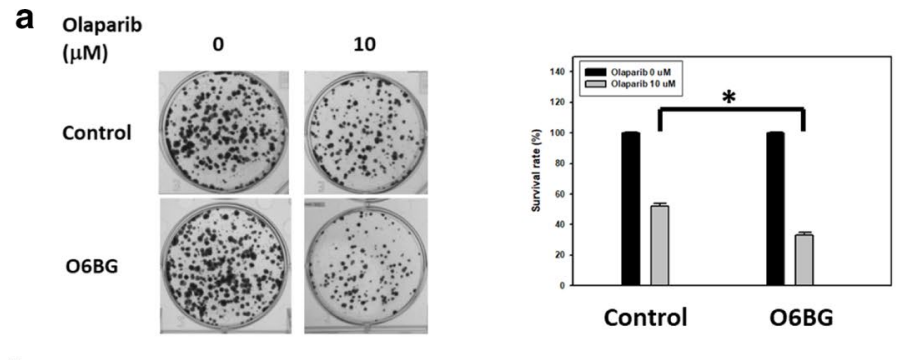

b Olaparib
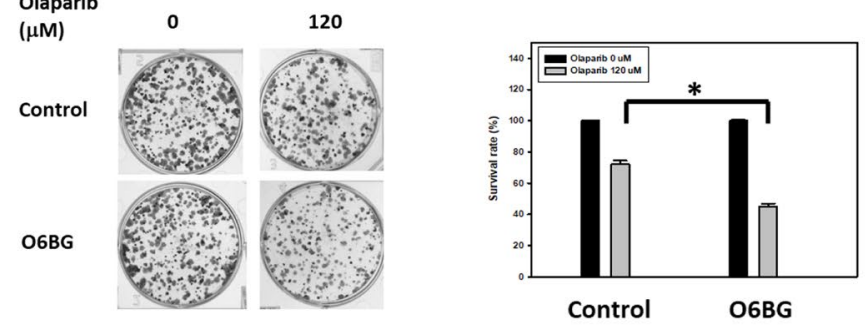

C
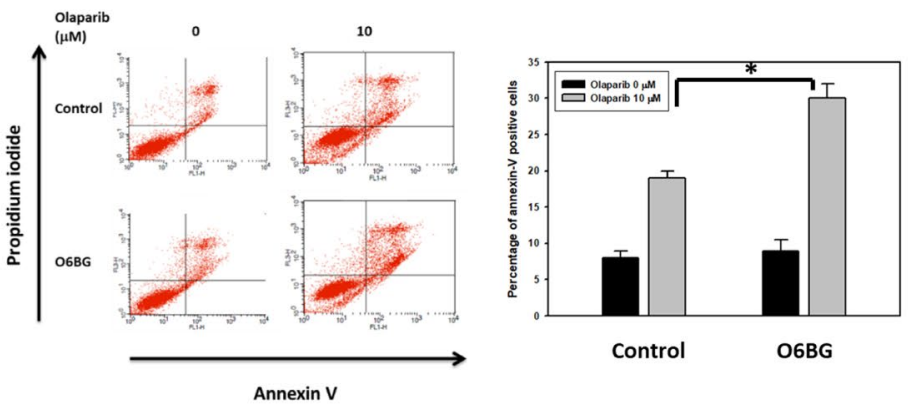

d
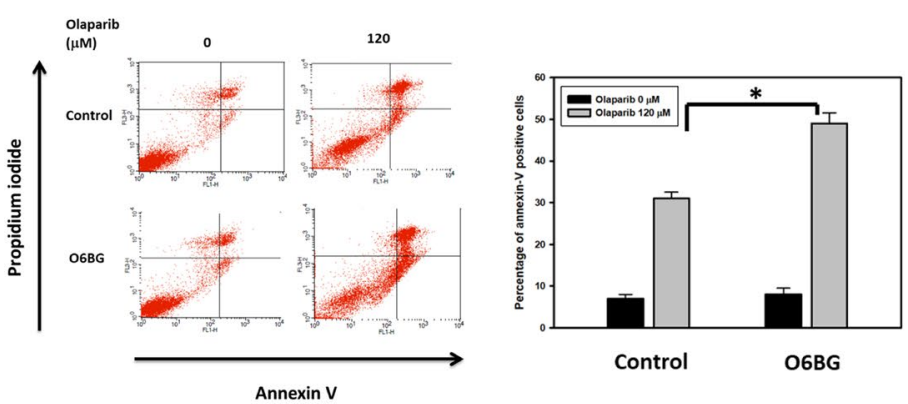

e

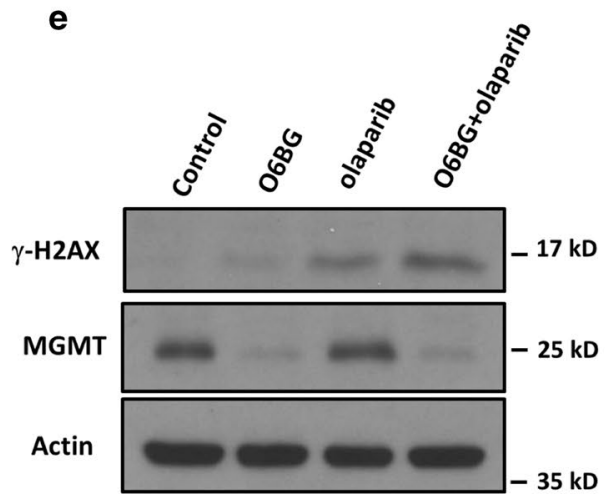

f
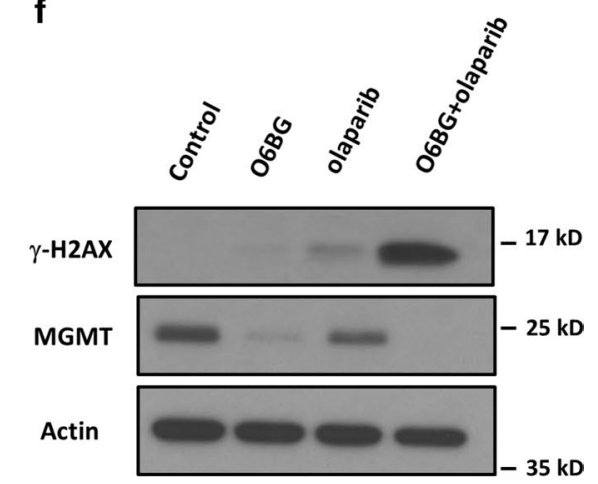


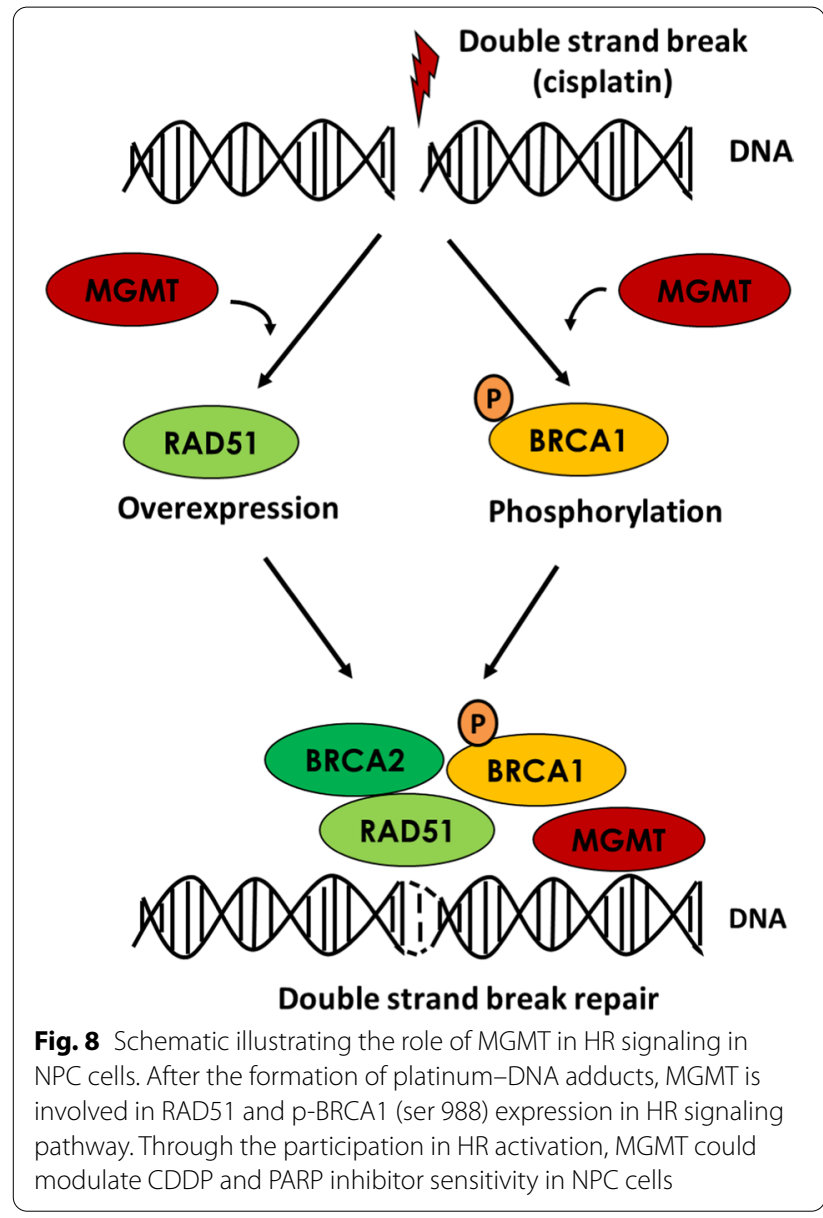

\section{Supplementary Information}

The online version contains supplementary material available at https://doi. org/10.1186/s12929-020-00699-y.

Additional file 1: Fig. S1. BRCA1 and BRCA2 expression in NPC cells treated with O6BG. a HONE-1 and $\mathbf{b}$ TW01 cells were treated with indicated concentrations of O6BG for $8 \mathrm{~h}$. The $\mathrm{IC}_{50}$ concentration of O6BG in both HONE-1 and TW01 cells was $120 \mu \mathrm{M}$. Cell lysates were subjected to Western blot analyses after the indicated treatment. Fold changes in protein levels listed under each blot were normalized to the levels of the actin control. Representative results of at least three independent experiments are shown. Fig. S2. MGMT interacted with BRCA2 in NPC cells treated with CDDP. After treatment with or without $10 \mu \mathrm{M}$ CDDP for $8 \mathrm{~h}$, the protein lysates of (A) HONE-1 and $\mathbf{b}$ TW01 cells were subjected to Co-IP analyses with $1 \mu \mathrm{g} / \mathrm{mL}$ of anti-MGMT antibodies, followed by Western blot analyses. Representative results of at least three independent experiments are shown. Fig. S3. MGMT mediated the cytotoxicity of PARP inhibitor in NPC cells. The a survival rates, $\mathbf{b}$ percentages of apoptotic cells, and $\mathbf{c}$ $\gamma$-H2AX expression of TW01 cells were examined using a clonogenic assay, annexin $\vee$ staining, and Western blot analyses. TW01 cells transfected with scrambled or MGMT-targeted siRNA were treated with olaparib for $24 \mathrm{~h}$. Representative histograms indicated the percentages of colony formation and apoptotic cells (annexin V-positive cells). Experiments were conducted at least three times. Bar values are presented as mean \pm SD. ${ }^{*} P<0.05$.

\section{Abbreviations}

NPC: Nasopharyngeal carcinoma; CDDP: Cisplatin; CRT: Chemoradiotherapy; NER: Nucleotide excision repair; DSB: Double-strand break; DDR: DNA damage response; HR: Homologous recombination; PARP: Poly(ADP-ribose) polymerase; SSB: Single-strand break; MGMT: O6-methylguanine-DNA methyltransferase; O6BG: O6-benzylguanine; q-PCR: Quantitative real-time PCR; siRNA: Small interfering RNA; Co-IP: Co-immunoprecipitation; PI: Propidium iodide; i.p.: Intraperitoneal; IHC: Immunohistochemistry; HRD: HR-deficient.

\section{Acknowledgements}

We thank the Bioimaging Core Facility of the National Core Facility for Biopharmaceuticals, Ministry of Science and Technology, Taiwan for their technical services.

\section{Authors' contributions}

SHC, WTH, WCK, SYH, YLS, CLC and CFL conceived and designed the experiments. SHC, WTH, CLC and CFL performed the data analyses and interpretation. SHC, HYP, CWF, YLS and CFL carried out the experiments. SHC, WTH, CLC and CFL contributed to manuscript writing. All authors read and approved the final manuscript.

\section{Funding}

This work was supported by grants from Chi Mei Medical Center, Liouying (CLFHR10821), the Ministry of Science and Technology, Taiwan (MOST 1042314-B-384-010 and MOST 104-2314-B-400-026), National Health Research Institutes, Taiwan (CA-106-PP-41), and the Health and Welfare surcharge of tobacco products (MOHW109-TDU-B-212-134020, WanFang Hospital, Chi Mei Medical Center, and Hualien Tzu-Chi Hospital Joing Cancer Center Grant-Focus on Colon Cancer Research).

\section{Availability of data and materials}

The dataset generated or analyzed in this study is included with this article and can be made available from the corresponding author upon reasonable request.

\section{Ethics approval and consent to participate}

All animal experiments were conducted according to the protocol approved by the Institutional Animal Care and Use Committee of Chi-Mei Medical Center (approval number: 102120606).

\section{Consent for publication}

Not applicable.

\section{Competing interests}

The authors declare that they have no competing interests.

\section{Author details}

${ }^{1}$ National Institute of Cancer Research, National Health Research Institutes, Tainan, Taiwan. ${ }^{2}$ Department of Oncology, National Cheng Kung University Hospital, College of Medicine, National Cheng Kung University, Tainan, Taiwan. ${ }^{3}$ Division of Hematology-Oncology, Department of Internal Medicine, Chi Mei Medical Center, Liouying, Tainan, Taiwan. ${ }^{4}$ Institute of Clinical Medicine, College of Medicine, National Cheng Kung University, Tainan, Taiwan. ${ }^{5}$ Institute of Biomedical Sciences, National Sun Yat-Sen University, Kaohsiung, Taiwan. ${ }^{6}$ Division of Colon and Rectal Surgery, Department of Surgery, Chi Mei Medical Center, No. 901, Zhonghua Rd., Yongkang Dist., Tainan 71004, Taiwan. ${ }^{7}$ Department of Medical Research, Chi Mei Medical Center, Tainan, Taiwan.

${ }^{8}$ Institute of Precision Medicine, National Sun Yat-sen University, No.70, Lien-hai Rd., Kaohsiung 80424, Taiwan.

Received: 6 July 2020 Accepted: 21 December 2020

Published online: 04 January 2021

\section{References}

1. Razak AR, Siu LL, Liu FF, Ito E, O'Sullivan B, Chan K. Nasopharyngeal carcinoma: the next challenges. Eur J Cancer. 2010;46:1967-78.

2. Lee CC, Huang TT, Lee MS, Su YC, Chou P, Hsiao SH, et al. Survival rate in nasopharyngeal carcinoma improved by high caseload volume: a nationwide population-based study in Taiwan. Radiat Oncol. 2011;6:92. 
3. Lee AW, Lin JC, Ng WT. Current management of nasopharyngeal cancer Semin Radiat Oncol. 2012;22:233-44.

4. Al-Sarraf M, LeBlanc M, Giri PG, Fu KK, Cooper J, Vuong T, et al. Chemoradiotherapy versus radiotherapy in patients with advanced nasopharyngeal cancer: phase III randomized Intergroup study 0099. J Clin Oncol. 1998;16:1310-7.

5. Kwong DL, Sham JS, Au GK, Chua DT, Kwong PW, Cheng AC, et al. Concurrent and adjuvant chemotherapy for nasopharyngeal carcinoma: a factorial study. J Clin Oncol. 2004;22:2643-53.

6. The NCCN Clinical Practice Guidelines in Oncology Home Page. https:// www.nccn.org. Accessed 15 May 2020.

7. Lee V, Kwong D, Leung TW, Lam KO, Tong CC, Lee A. Palliative systemic therapy for recurrent or metastatic nasopharyngeal carcinoma-how far have we achieved? Crit Rev Oncol Hematol. 2017;114:13-23.

8. Dasari S, Tchounwou PB. Cisplatin in cancer therapy: molecular mechanisms of action. Eur J Pharmacol. 2014;740:364-78.

9. Chen SH, Chang JY. New insights into mechanisms of cisplatin resistance: from tumor cell to microenvironment. Int J Mol Sci. 2019. https://doi. org/10.3390/ijms20174136.

10. Rocha CRR, Silva MM, Quinet A, Cabral-Neto JB, Menck CFM. DNA repair pathways and cisplatin resistance: an intimate relationship. Clinics (Sao Paulo). 2018;73(suppl 1):e478s. https://doi.org/10.6061/clinics/2018/ e478s.

11. Wright WD, Shah SS, Heyer WD. Homologous recombination and the repair of DNA double-strand breaks. J Biol Chem. 2018;293:10524-35.

12. Yap TA, Plummer R, Azad NS, Helleday T. The DNA damaging revolution: PARP inhibitors and beyond. Am Soc Clin Oncol Educ Book. 2019;39:185-95

13. Mateo J, Lord CJ, Serra V, Tutt A, Balmaña J, Castroviejo-Bermejo M, et al. A decade of clinical development of PARP inhibitors in perspective. Ann Oncol. 2019;30:1437-47.

14. Wang QE, Milum K, Han C, Huang YW, Wani G, Thomale J, et al. Differential contributory roles of nucleotide excision and homologous recombination repair for enhancing cisplatin sensitivity in human ovarian cancer cells. Mol Cancer. 2011. https://doi.org/10.1186/1476-4598-10-24.

15. Cavallo F, Graziani G, Antinozzi C, Feldman DR, Houldsworth J, Bosl GJ, et al. Reduced proficiency in homologous recombination underlies the high sensitivity of embryonal carcinoma testicular germ cell tumors to Cisplatin and poly (adp-ribose) polymerase inhibition. PLOS ONE. 2012. https://doi.org/10.1371/journal.pone.0051563.

16. Birkelbach M, Ferraiolo N, Gheorghiu L, Pfäffle HN, Daly B, Ebright MI, et al. Detection of impaired homologous recombination repair in NSCLC cells and tissues. J Thorac Oncol. 2013;8:279-86.

17. Kaina B, Margison GP, Christmann M. Targeting $\mathrm{O}^{6}$-methylguanine-DNA methyltransferase with specific inhibitors as a strategy in cancer therapy. Cell Mol Life Sci. 2010;67:3663-81.

18. Chen SH, Kuo CC, Li CF, Cheung CH, Tsou TC, Chiang HC, et al. O(6)methylguanine DNA methyltransferase repairs platinum-DNA adducts following cisplatin treatment and predicts prognoses of nasopharyngeal carcinoma. Int J Cancer. 2015;137:1291-305.

19. Martinelli CMDS, Lengert AVH, Cárcano FM, Silva ECA, Brait M, Lopes $L F$, et al. MGMT and CALCA promoter methylation are associated with poor prognosis in testicular germ cell tumor patients. Oncotarget. 2016;8:50608-17.

20. Vitellius $C$, Eymerit-Morin C, Luet D, Fizanne L, Foubert F, Bertrais S, et al. Relationship between the expression of O6-methylguanine-DNA methyltransferase (MGMT) and p53, and the clinical response in metastatic pancreatic adenocarcinoma treated with FOLFIRINOX. Clin Drug Investig. 2017:37:669-77.

21. Zhang J, Zhu Y, Wang Y, Fu Q, Xie H, Liu Z, et al. Prognostic and predictive value of O6-methylguanine methyltransferase for chemotherapy in patients with muscle-invasive bladder cancer. Ann Surg Oncol. 2018;25:342-8.

22. Philip S, Swaminathan S, Kuznetsov SG, Kanugula S, Biswas K, Chang S, et al. Degradation of BRCA2 in alkyltransferase-mediated DNA repair and its clinical implications. Cancer Res. 2008;68:9973-81.

23. Glaser R, Zhang HY, Yao KT, Zhu HC, Wang FX, Li GY, et al. Two epithelial tumor cell lines (HNE-1 and HONE-1) latently infected with Epstein-Bar virus that were derived from nasopharyngeal carcinomas. Proc Natl Acad Sci USA. 1989:86:9524-8.
24. Lin CT, Wong Cl, Chan WY, Tzung KW, Ho JK, Hsu MM, et al. Establishment and characterization of two nasopharyngeal carcinoma cell lines. Lab Invest. 1990:62:713-24.

25. Zhang L, Maclsaac KD, Zhou T, Huang PY, Xin C, Dobson JR, et al. Genomic analysis of nasopharyngeal carcinoma reveals TME-based subtypes. Mol Cancer Res. 2017;15:1722-32.

26. Hsu SH, Chen SH, Kuo CC, Chang JY. Ubiquitin-conjugating enzyme E2 $B$ regulates the ubiquitination of O6-methylguanine-DNA methyltransferase and BCNU sensitivity in human nasopharyngeal carcinoma cells. Biochem Pharmacol. 2018;158:327-38.

27. Jabbour-Leung NA, Chen X, Bui T, Jiang Y, Yang D, Vijayaraghavan S, et al. Sequential combination therapy of CDK inhibition and doxorubicin is synthetically lethal in p53-mutant triple-negative breast cancer. Mol Cancer Ther. 2016;15:593-607.

28. Lin TY, Chan HH, Chen SH, Sarvagalla S, Chen PS, Coumar MS, et al. BIRC5/ Survivin is a novel ATG12-ATG5 conjugate interactor and an autophagyinduced DNA damage suppressor in human cancer and mouse embryonic fibroblast cells. Autophagy. 2020;16(7):1296-313.

29. Ouchi T. BRCA1 phosphorylation: biological consequences. Cancer Biol Ther. 2006:5:470-5.

30. Roy R, Chun J, Powell SN. BRCA1 and BRCA2: different roles in a common pathway of genome protection. Nat Rev Cancer. 2011;12:68-78.

31. Vaddepally RK, Kharel P, Pandey R, Garje R, Chandra AB. Review of indications of FDA-approved immune checkpoint inhibitors per NCCN guidelines with the level of evidence. Cancers (Basel). 2020;20(12):738. https://doi.org/10.3390/cancers12030738.

32. Burtness B, Harrington KJ, Greil R, Soulières D, Tahara M, de Castro Jr G, et al. Pembrolizumab alone or with chemotherapy versus cetuximab with chemotherapy for recurrent or metastatic squamous cell carcinoma of the head and neck (KEYNOTE-048): a randomised, open-label, phase 3 study. Lancet. 2019:394:1915-28.

33. Jackson SP, Bartek J. The DNA-damage response in human biology and disease. Nature. 2009:461:1071-8.

34. Wang LG, Setlow RB. Inactivation of O6-alkylguanine-DNA alkyltransferase in HeLa cells by cisplatin. Carcinogenesis. 1989;10:1681-4.

35. Fishel ML, Delaney SM, Friesen LD, Hansen RJ, Zuhowski EG, Moschel RC, et al. Enhancement of platinum-induced cytotoxicity by O6-benzylguanine. Mol Cancer Ther. 2003;2:633-40.

36. Fishel ML, Newell DR, Griffin RJ, Davison R, Wang LZ, Curtin NJ, et al. Effect of cell cycle inhibition on Cisplatin-induced cytotoxicity. J Pharmacol Exp Ther. 2005;312:206-13.

37. Wilk A, Waligorska A, Waligorski P, Ochoa A, Reiss K. Inhibition of ERß induces resistance to cisplatin by enhancing Rad51-mediated DNA repair in human medulloblastoma cell lines. PLoS ONE. 2012;7:e33867. https:// doi.org/10.1371/journal.pone.0033867.

38. Chen Q, Cai D, Li M, Wu X. The homologous recombination protein RAD51 is a promising therapeutic target for cervical carcinoma. Oncol Rep. 2017;38:767-74.

39. Wang J, Che W, Wang W, Su G, Zhen T, Jiang Z. CDKN3 promotes tumor progression and confers cisplatin resistance via RAD51 in esophageal cancer. Cancer Manag Res. 2019:11:3253-64.

40. Lee JO, Kang MJ, Byun WS, Kim SA, Seo IH, Han JA, et al. Metformin overcomes resistance to cisplatin in triple-negative breast cancer (TNBC) cells by targeting RAD51. Breast Cancer Res. 2019;21:115. https://doi. org/10.1186/s13058-019-1204-2.

41. Vítor AC, Huertas P, Legube G, de Almeida SF. Studying DNA doublestrand break repair: an ever-growing toolbox. Front Mol Biosci. 2020;7:24. https://doi.org/10.3389/fmolb.2020.00024.

42. Ohba S, Mukherjee J, See WL, Pieper RO. Mutant IDH1-driven cellular transformation increases RAD51-mediated homologous recombination and temozolomide resistance. Cancer Res. 2014;74:4836-44.

43. Yu W, Zhang L, Wei Q, Shao A. O6-methylguanine-DNA methyltransferase (MGMT): challenges and new opportunities in glioma chemotherapy. Front Oncol. 2020:9:1547. https://doi.org/10.3389/fonc.2019.01547.

44. Quinn JA, Desjardins A, Weingart J, Brem H, Dolan ME, Delaney SM, et al. Phase I trial of temozolomide plus O6-benzylguanine for patients with recurrent or progressive malignant glioma. J Clin Oncol. 2005;23:7178-87.

45. Quinn JA, Jiang SX, Reardon DA, Desjardins A, Vredenburgh JJ, Rich JN, et al. Phase I trial of temozolomide plus O6-benzylguanine 5-day regimen with recurrent malignant glioma. Neuro Oncol. 2009:11:556-61. 
46. Broniscer A, Gururangan S, MacDonald TJ, Goldman S, Packer RJ, Stewart $\mathrm{CF}$, et al. Phase I trial of single-dose temozolomide and continuous administration of o6-benzylguanine in children with brain tumors: a pediatric brain tumor consortium report. Clin Cancer Res. 2007;13(22 Pt 1):6712-8.

47. Quinn JA, Jiang SX, Carter J, Reardon DA, Desjardins A, Vredenburgh JJ, et al. Phase II trial of gliadel plus O6-benzylguanine in adults with recurrent glioblastoma multiforme. Clin Cancer Res. 2009;15:1064-8.

48. Miller RP, Tadagavadi RK, Ramesh G, Reeves WB. Mechanisms of cisplatin nephrotoxicity. Toxins (Basel). 2010;2:2490-518.

49. Preuss I, Haas S, Eichhorn U, Eberhagen I, Kaufmann M, Beck T, et al. Activity of the DNA repair protein O6-methylguanine-DNA methyltransferase in human tumor and corresponding normal tissue. Cancer Detect Prev. 1996;20(2):130-6.

50. Telli ML, Timms KM, Reid J, Hennessy B, Mills GB, Jensen KC, et al. Homologous recombination deficiency (HRD) score predicts response to platinum-containing neoadjuvant chemotherapy in patients with triplenegative breast cancer. Clin Cancer Res. 2016;22:3764-73.
51. Knijnenburg TA, Wang L, Zimmermann MT, Chambwe N, Gao GF, Cherniack AD, et al. Genomic and molecular landscape of DNA damage repair deficiency across the Cancer Genome Atlas. Cell Rep. 2018;23:239-54.

52. Pellegrino B, Mateo J, Serra V, Balmaña J. Controversies in oncology: are genomic tests quantifying homologous recombination repair deficiency (HRD) useful for treatment decision making? ESMO Open. 2019;4:e000480. https://doi.org/10.1136/esmoopen-2018-000480.

\section{Publisher's Note}

Springer Nature remains neutral with regard to jurisdictional claims in published maps and institutional affiliations.
Ready to submit your research? Choose BMC and benefit from:

- fast, convenient online submission

- thorough peer review by experienced researchers in your field

- rapid publication on acceptance

- support for research data, including large and complex data types

- gold Open Access which fosters wider collaboration and increased citations

- maximum visibility for your research: over $100 \mathrm{M}$ website views per year

At BMC, research is always in progress.

Learn more biomedcentral.com/submissions 